\title{
¿PARA QUÉ SIRVE EL DERECHO SI INCORPORA A LA MORAL?
}

\author{
WHAY DO WE NEED LAW, IF IT INCORPORATES MORALS?
}

\author{
Juan Cianciardo \\ Pilar Zambrano ${ }^{1}$
}

\begin{abstract}
RESUMEN: Una vez que se acepta con Hart que el Derecho se propone regular la conducta humana vinculando con la misma fuerza obligatoria (categórica) con que vinculan las razones morales, la cuestión de la distinción entre el Derecho y la moral emerge con una claridad inocultable. Surgen, al menos, dos tipos de preguntas: ¿son relevantes las normas jurídicas para la justificación de la acción, o acaso las normas morales poseen una fuerza justificatoria autónoma y suficiente? En segundo lugar, ¿̨hace alguna diferencia el Derecho en la deliberación práctica, si su interpretación implica una conexión de sentido con las normas morales? En este trabajo se describe en detalle la original y anticipada respuesta de Carlos S. Nino a este doble orden de preguntas (secciones 1-3). Se propone asimismo una crítica, que podría resumirse en la identificación de una doble paradoja a la que conduce el escepticismo epistémico de Nino. Por una parte, en su intento por salvar el legado de Hart de la superficialidad, Nino se repliega hasta la posición de Kelsen, dejando en el camino no ya la relevancia de la fuerza categórica del Derecho, sino su propia fuerza categórica. Intentando mostrar que las razones jurídicas para la acción son relevantes para su justificación moral, acaba por mostrar que el Derecho carece de toda capacidad de justificar moralmente el obrar (sección 4).

En segundo lugar, el intento paralelo por salvar el legado hartiano de la irrelevancia en el orden deliberativo, agrava las debilidades de la teoría interpretativa dworkiniana, tornando irrelevante como guía para la acción, no ya al Derecho, sino a la moral. Intentando mostrar que el Derecho hace una diferencia en la deliberación práctica, la propuesta de Nino conduce a negar que la moral guíe el obrar en absoluto en el plano de la acción social (sección 5).
\end{abstract}

Palabras clave: Relevancia del Derecho, Derecho y moral, derechos constitucionales, punto de vista interno y punto de vista externo.

ABSTRACT: If we accept with Hart that Law intends to regulate human behaviour with the same categorical force that Morals does, the question concerning the distinction between Law and Morals can be split into at least two more specific kinds of inquiries: (a) Are legal reasons distinguishable from moral reasons for action, once it is admitted that both claim to have the same peremptory and categorical force? (b) What do legal reasons for action aggregate to practical deliberation, once it is also admitted that legal interpretation incorporates moral interpretation? This article discusses Nino's answer to this double stage of questions,

${ }^{1}$ Los autores son investigadores del Consejo Nacional de Investigaciones Científicas y Técnicas de la Argentina (CONICET) y de la Universidad Austral (Argentina). Una parte de esta investigación la llevaron adelante como Research Fellow del Instituto Cultura y Sociedad de la Universidad de Navarra (España). Deseamos expresar nuestro agradecimiento a los profesores Caridad Velarde, Alejandro Vigo, Pablo Sánchez Ostiz, Pedro Rivas, Juan B. Etcheverry y Aitor Rodríguez Salaverría por haberse prestado a la discusión de algunas de las ideas contenidas en este trabajo. Damos gracias, asimismo, a los evaluadores anónimos de la Revista Chilena de Derecho por sus valiosas observaciones y sugerencias. Dirección postal: Mariano Acosta s/n y Ruta Nacional 8 (B1629WWA) Pilar, Buenos Aires, Argentina. Dirección electrónica:: jcianciardo@ius.austral.edu.ar; pzambrano@ius.austral.edu.ar 
and develops a critical relfection which could be summarized as follows: Nino's epistemic skepticism leads to a double paradox. In trying to save Hart's heritage from Law's justificatory irrelevance, he steps back to Kelsen's position and looses not just the relevance of Law's categorical force but its same categorical force (section 4). And in trying to save Hart's heritage from Law's deliberative superfluity, he deepens the queries of Dworkin's interpretative theory, turning irrelevant not Law's guiding capacity in the field of social action, but that of morals (section 5).

Key words: Relevance of Law, Law and Moral, Constitutional Rights, Internal and External Point of View.

\section{INTRODUCCIÓN: LA ADOPCIÓN DEL PUNTO DE VISTA INTERNO Y EL PROBLEMA DE LA RELEVANCIA DEL DERECHO}

Varias de las notas actuales de la "cultura de derechos" por la que transitamos generan problemas filosóficos. Hay, incluso, un consenso más o menos evidente acerca de que sobre ellas gira el eje del debate de la Teoría del Derecho contemporánea ${ }^{2}$. Algunos de esos rasgos muestran una conexión de sentido y de justificación entre el Derecho y un orden moral independiente de toda praxis humana (en adelante, OMI): el lenguaje de los textos jurídicos en los que se reconocen derechos humanos -en el que se emplea, precisamente, la expresión "reconocimiento", y no "creación" o "invento"3-, la fuerza difusiva y vinculante de los principios constitucionales y convencionales sobre el orden infraconstitucional -que conduce a problemas que no se pueden resolver tomando como único parámetro los textos positivos-, las exigencias de razonabilidad y proporcionalidad en la creación y aplicación del Derecho -cuya estrecha relación con la argumentación moral es bastante evidente-, y la conexión entre las prácticas constitucionales y las prácticas convencionales de derechos humanos ${ }^{4}$.

Entre las muchas preguntas que plantea este estado de cosas, se impone por su propio peso la cuestión por la relevancia del Derecho. Si el Derecho guía y coordina la conducta humana mediante la referencia a un OMI, ¿cuál es entonces su función? ¿Por qué no dejarnos guiar simplemente por el OMI, en lugar de instaurar la complejísima práctica social del Derecho? ¿Por qué no coordinar la conducta humana y resolver conflictos recurriendo sin más al OMI? Yendo más lejos aún: incluso en el caso de que se acepte que cabe para el Derecho alguna función que justifique o dé cuenta de su relevancia más allá de cualquier circunstancia concreta, vale la pena preguntarse hasta qué punto esa función resulta oscurecida o amenazada específicamente en contextos como el actual, signados entre otras cosas por la (omni) presencia de los rasgos reseñados en el párrafo precedente. O dicho con otras palabras, ¿no podría pensarse que cuanto más neoconstitucionalismo y neoconvencionalismo

\footnotetext{
${ }^{2}$ Según Alex Stone Sweet, la "fórmula básica" de esa nueva cultura es: "una Constitución escrita, profundamente arraigada, una declaración de derechos fundamentales, y algún modo de control de constitucionalidad judicial que permita proteger esos derechos". STONE SWEET (2012) p. 816.

3 Cfr. Hervada (1982) pp. 243-256.

${ }^{4}$ Cfr., al respecto, Cianciardo y Zambrano (2014).

Con este grado de generalidad, la afirmación del texto podría probablemente ser suscripta por algunos de los más relevantes filósofos del Derecho contemporáneos. Cfr., por ejemplo, DwORKIN (2011) pp. 191-218; AleXY (2008) pp. 281-299; NiNO (1994) cap. 1.
} 
exista, es decir, cuanto mayor sea la función que prima facie corresponde al OMI, menos relevancia tendrá el Derecho? Desde otro ángulo de análisis, las preguntas y los temores apuntan al papel que desempeñan los jueces: la aceptación de la existencia de un OMI con el que el Derecho necesariamente se vincula, ¿no conduce de modo inevitable a un gobierno de los jueces? ¿No es una prueba de esto último (y de los riesgos que conlleva) la influencia creciente de los tribunales con jurisdicción constitucional en decisiones que la Teoría constitucional consideró durante muchos años reservadas al Congreso o al Poder Ejecutivo?

La pregunta por la relevancia del Derecho es, en definitiva, una pregunta por su identidad, por aquello que permite distinguirlo de otras formas de coexistencia, como la amistad, la caridad o la política. Este interrogante y los que se derivan de él no son, naturalmente, inquietudes nuevas. Su enfoque correcto requiere tener presente, sin embargo, lo que hace ya varios años advertía Javier de Lucas: la pregunta por el ser del Derecho (¿qué es el Derecho?) no tiene carácter originario. En su opinión, "admitirla como la cuestión previa solo es posible cuando se olvida el auténtico problema inicial, la pregunta fundamental. En efecto, parafraseando a Heidegger, se trataría de saber por qué es el Derecho, y no, más bien, la ausencia de Derecho"5. O más precisamente, como sugirió Cotta, se trataría se saber para qué está el Derecho, y en qué se diferencia de la violencia, en un extremo, y de la moral, en otro, como modo de coordinación de la conducta ${ }^{6}$.

Durante mucho tiempo el positivismo se empeñó en distinguir al Derecho de otros órdenes normativos, y en particular de la moral, a partir de elementos formales como la coacción, el origen social de la norma, o la forma de la norma (imperativa). Se trataba, en el fondo, de construir una teoría "pura" del Derecho que no tomara en consideración como factor de especificación elementos materiales o morales, incapaces de satisfacer los estrictos cánones de legitimación racional de la ciencia moderna. El enfoque variaría parcialmente luego con el advenimiento del positivismo analítico, de modo especial a partir de las reflexiones de Hart y de su discípulo Raz. Estos autores pusieron el eje de la distinción entre el Derecho y la moral en la incidencia peculiar del Derecho como orden regulador de la conducta sobre el razonamiento práctico de sus partícipes. Su punto de partida fue la siguiente pregunta: ¡ofrece el Derecho motivos para obrar distintos de los motivos que ofrece la moral? En muy resumidas cuentas, este viraje -esta llamada a examinar el problema desde el "punto de vista interno"- supuso una atención a las "razones para obedecer al Derecho", que hasta ese momento habían quedado algo descuidadas en el seno del positivismo analítico ${ }^{7}$. La cuestión de la distinción entre Derecho y moral se enfocó, en fin, no tanto ni únicamente en la fuente u origen de uno y otro orden, o en su vínculo con la coacción, sino más bien en lo específico o distintivo de las razones para obrar que emergen de ambos sistemas normativos.

5 De LuCAS (1982) p. 122.

6 Cfr. CotTa (1991) pp. 10-14. Esta indagación por los fines es lo que hace de la Filosofía del Derecho, propiamente, Filosofía. Cfr., al respecto, Romano (2010) pp. 11-20.

7 Cfr. Hart (1994) p. 56 ss. Aunque la casi totalidad de la obra de Raz constituye un análisis del Derecho desde la perspectiva interna, entre algunos de los trabajos más específicamente dirigidos a desarrollar este punto pueden nombrarse los siguientes: Raz (1999), reeditado de su edición original de 1975 en 1990 por Princeton University Press y en 1999 por Oxford University Press; (1979), que se cita aquí en la versión en español (1991); (1986), caps. 1-4; (2001) pp. 1-18; (2004) pp 1-17; y (2006) pp. 1003-1045. 
El estudio del Derecho a partir del concepto "de razón para la acción” se constituyó rápidamente en uno de los ejes centrales del debate iusfilosófico, en especial, como se mencionó, en el ámbito anglosajón (y luego, por su influencia, en el resto de los ámbitos científicos), muy probablemente como consecuencia de la necesidad de superar las ambigüedades e imprecisiones que suelen acompañar a cualquier cambio conceptual drástico ${ }^{8}$. Las discusiones parten del consenso existente en torno a la relación de género y especie entre la naturaleza de un motivo para obrar y la naturaleza de una razón para la acción. Mientras que el motivo abarca toda clase de determinación interior para la acción, la razón es un tipo especial de motivación que incluye la conciencia de obligatoriedad. Y no cualquier clase de obligatoriedad, sino la obligatoriedad categórica (obliga por sí misma, y no por su relación instrumental con otros fines) y perentoria (no es derrotable por otra clase de motivaciones).

En otras palabras, quien encuentra una razón para actuar $X$, entiende que $X$ es obligatorio en sí mismo, o es el modo de realizar otros fines que son obligatorios en sí mismos (es una razón categórica). Además, entiende que su obligatoriedad no cede frente a motivaciones pasionales o emotivas, que a grandes trazos podrían sintetizarse en el concepto de interés (es perentoria). Una razón para actuar $X$ no está condicionada por el interés personal, ni emerge de motivos distintos de la conciencia de su intrínseca obligatoriedad?

Por todo lo dicho, afirmar que el Derecho ofrece "razones para la acción" implica también afirmar que pretende regular la conducta humana vinculando con la misma fuerza obligatoria con que vinculan las razones morales, y no solo ni principalmente generando temor, como pretendía, por ejemplo, Austin ${ }^{10}$. Situados en este plano, por un lado, y aceptando que el caso típico de "razón para actuar" es el de la razón moral -puesto que típicamente pretende tanto obligatoriedad categórica como perentoriedad-, por otro, la cuestión de la distinción entre Derecho y moral emerge con una claridad e indispensabilidad inocultables. Surgen, al menos, dos tipos de preguntas: ¿qué diferencia a la razón jurídica de la razón moral para actuar, una vez que se advierte que una y otra poseen la misma fuerza categórica y perentoria? Más aún, ¿qué distingue a la razón jurídica de la razón moral para actuar, una vez que se advierte, como se ha hecho al comienzo, que la razón jurídica condiciona su fuerza perentoria y categórica a su conexión material con un OMI?

Uno de los filósofos que ha abordado estas preguntas de modo más directo e interesante ha sido el argentino Carlos Nino, a través de un intento por superar la llamada "paradoja de la irrelevancia" ${ }^{11}$. Según esta paradoja, en un sentido muy general, si el Derecho estuviera conectado con la moral entonces sería irrelevante, porque bastaría con la moral para

\footnotetext{
${ }^{8}$ Cfr. Zambrano (sobre el giro que representa la obra de Hart en la filosofía del Derecho positivista y no positivista, y sobre el carácter relativamente inexplorado de las consecuencias de este giro puede confrontarse Burton (1989) p. 748; y, algo más recientemente, Perry (2005) pp. 264-265. Sobre las ambigüedades en el concepto raziano de "razón excluyente para la acción", pueden consultarse MoORe (1989) p. 854 ss.; y PerRY (2005) p. 941 ss. Las respuestas de Raz a estas observaciones pueden consultarse en RAZ (1989) p. 1156 ss.

9 Sobre la distinción conceptual entre razones y motivos para la acción, ver más ampliamente ZAmBrano (2012) pp. 71-80.

${ }^{10}$ Cfr., por ejemplo, Austin (1981) pp. 23-36.

${ }^{11}$ Con respecto a la expresión "la paradoja de la irrelevancia", cfr. RódenAs (1991) pp. 279-293; de la misma autora, Ródenas (1996) pp. 226 y ss. Asimismo, Grepri (2008) pp. 221-259, esp. pp. 232-238. Raz alude a esto mismo en RAZ (1991) pp. 242 y 155.
} 
resolver los problemas de coordinación a los que el Derecho se refiere. Nino trató el tema en varias oportunidades, entre las que destacan dos: el artículo "La paradoja de la irrelevancia moral del gobierno y el valor epistemológico de la democracia", publicado inicialmente en 198612; y el libro Derecho, Moral y Política. Una revisión de la teoría general del Derecho ${ }^{13}$, publicado en 1994, luego de su muerte. En el primer caso el profesor argentino partió de la pregunta sobre la justificación moral de la democracia, "en el sentido de regla de la mayoría" ${ }^{4}$, como vía para justificar la obligatoriedad moral del Derecho sin frustrar su relevancia. En el segundo, en cambio, el punto de partida fue el análisis de la posible "conexión directa” entre el Derecho y la política, y del lugar o función específica que le toca al Derecho en la regulación de la conducta una vez que se admite que está materialmente ligado con una teoría moral de lo justo (la política) ${ }^{15}$. En uno y otro trabajo, Nino identificó los presupuestos o postulados a priori de la pregunta por la relevancia del Derecho frente a la moral.

Lo valioso del aporte de Nino radica en la precisión con distinguió y al mismo tiempo conectó las dos dimensiones de esa pregunta: por una parte, el problema del papel del Derecho como razón para la acción; por otra, el problema del papel del Derecho en la deliberación práctica que acaba con la identificación del tipo de acción imperada.

Lo primero fue tratado por Nino como la "paradoja de la superfluidad del Derecho" consistente en que, "si para que una norma jurídica justifique una acción o decisión debemos inevitablemente mostrar que emana de principios morales que se asumen como válidos ¿por qué no buscar la justificación de esa acción o decisión directamente en esos mismos principios? ¿Para qué necesitamos, al fin y al cabo, un gobierno y sus leyes si estas no permiten justificar una acción más que recurriendo, en última instancia, a principios morales?". Efectivamente, al menos a primera vista, "si las leyes coinciden con tales principios son redundantes, y si no coinciden no se les debe prestar atención" ${ }^{16}$.

La segunda paradoja consiste, también, en un cuestionamiento de la relevancia del gobierno y de sus leyes. Se trata de una paradoja causada por la "indeterminación radical" del Derecho. Nino explica que si se abstraen todos los pasos valorativos de la interpretación el único "dato duro" que podría condicionar el proceso interpretativo consiste en textos o conductas, es decir, en gráficos o movimientos corporales. "Dadas las opciones de criterios generales de interpretación para dotar de significado a tales entidades o eventos, las alternativas para superar las imprecisiones o ambigüedades de esos significados, las variantes para superar las indeterminaciones lógicas, los textos y conductas en cuestión pueden estar asociadas con cualquier contenido proposicional, según los principios valorativos asumidos en cada paso" 17 . Por ello, sin acudir a consideraciones extranormativas ("extrajurídicas" las llama Nino) no parece posible superar la opacidad de los textos. Esto conduce a nuestro autor a preguntarse, nuevamente, por la relevancia del Derecho positivo, "entendido como

12 Nino (1986) pp. 65-82. Este trabajo fue publicado luego en NinO (1989) pp. 111-133, lugar del que se citará aquí. Existe, asimismo, una versión en inglés con algunas diferencias respecto del texto inicial: (1991) pp. 36-51.

${ }_{13}$ Nino (1994) pp. 130-160.

${ }^{14}$ Nino (1986) p. 113.

15 Nino (1994) p. 130.

${ }_{16}$ Nino (1994) p. 131.

17 Nino (1994) p. 133. 
actos lingüísticos, textos o prácticas, dado que las proposiciones que les asignamos como significados van a depender totalmente de los principios valorativos que adoptemos. ¿Por qué no acudir directamente a tales principios valorativos para obtener las soluciones deseadas, en lugar de hacerlas aparecer como si surgieran del texto?" ${ }^{18}$. El intérprete nada podría hacer con el Derecho sin que su interpretación se nutra de la moral. Incluso, lo realmente significativo de su tarea provendría en última instancia de allí.

En suma, se plantean dos paradojas que ponen en cuestión la relevancia del Derecho: si el Derecho tiene una relación justificatoria con la moral, entonces no aporta razones para la acción distintas de las razones morales, y deviene superfluo; y si tiene una relación interpretativa, entonces es irrelevante. La primera de las paradojas surge en el plano de la normatividad del Derecho, la segunda, en el de su interpretación. Se trata, en realidad, de dos formas de aproximarse al mismo problema, de dos modos de cuestionar la aportación del Derecho al razonamiento práctico.

Como ya se ha dicho, la propuesta de Nino constituye, por la precisión y la extensión de su análisis, un excelente punto de partida para aproximarse a una respuesta posible a la siguiente pregunta: una vez que se advierte que la cultura de derechos conecta tanto su sentido interpretativo como su cadena de normatividad,validez y obligatoriedad, con un OMI; ¿por qué hemos de dejarnos guiar por el Derecho y no más bien por la moral?

En las páginas siguientes (secciones 1-3) se abordarán las ideas del autor sobre las dos paradojas. El detalle de la descripción se justifica, de un parte, por la minuciosidad con que Nino identificó los argumentos que sostienen las paradojas, distinguiendo el nivel de debate en que se sitúa cada uno, de un modo que es aún hoy original. En segundo lugar, por otra parte, la descripción pretende mostrar la propuesta del autor "en su mejor luz", por utilizar la conocida expresión de Dworkin, de forma tal que la crítica que se emprenderá en los epígrafes siguientes no acabe por desdibujar su objeto.

Esta crítica podría resumirse en la identificación de una nueva doble paradoja a la que conduce el escepticismo epistémico de Nino. Por una parte, en su intento por salvar el legado de Hart de la superficialidad, Nino se repliega hasta la posición de Kelsen, dejando en el camino no ya la relevancia del Derecho como razón categórica (moral) para la acción, sino su propia fuerza categórica. Intentando mostrar que las razones morales que el Derecho aporta son relevantes, Nino acaba por mostrar que el Derecho no aporta razones para obrar sino, como mucho, motivos (sección 4).

En segundo lugar, el intento paralelo por salvar el legado hartiano de la irrelevancia agrava las debilidades de la propuesta dworkiniana, tornando irrelevante como guía para la acción, no ya al Derecho, sino a la moral. Intentando mostrar que el Derecho guía la conducta en forma complementaria o al menos paralela a la moral, la propuesta de Nino conduce a negar que la moral guíe el obrar en absoluto (sección 5).

\footnotetext{
18 Nino (1994) pp. 133-134. Nino desarrolló en otro trabajo suyo una crítica profunda y sugerente de lo que definió como una "preocupación recurrente de los juristas dogmáticos acerca del carácter científico de su actividad”, preocupación que explicaría actitudes como la que implícitamente se critica con la pregunta formulada en el texto. Luego de negar la pretendida cientificidad (more moderno) para el Derecho, Nino propuso el reemplazo de dicha preocupación por "una búsqueda legítima de analogías y diferencias con las actividades reconocidas como científicas”. Cfr. Nino (1989) pp. 9-16.
} 


\section{LA NORMATIVIDAD DEL DERECHO, LA RELEVANCIA DEL DERECHO COMO RAZÓN PARA LA ACCIÓN Y LOS PRESUPUESTOS DE LA PRIMERA PARADOJA}

Avancemos, pues, con la formulación del problema. Nino advierte que cualquier intento de justificar la obligatoriedad del Derecho "debe mostrar que la obligatoriedad deriva de otras normas cuya obligatoriedad no depende a su vez de normas ulteriores o del hecho de que sean obedecidas o reconocidas" ${ }^{19}$, puesto que la primera alternativa conduciría a una derivación infinita, y la segunda a una falacia. Esta clase de obligatoriedad es, en opinión de Nino, una característica de los principios morales. "En otras palabras, cuando preguntamos por la obligatoriedad de las normas jurídicas, estamos preguntando por su obligatoriedad moral, o sea por los principios morales que, bajo ciertas condiciones a esclarecer, prescriben que debemos obedecer tales reglas" 20.

Sobre este plano describe una paradoja, que califica como aparente: "si para decidir o no obedecer las normas jurídicas necesitamos recurrir a principios morales que determinan si ellas son o no obligatorias -o lo que es lo mismo, si debe o no realizarse lo que ellas disponen- ¿para qué son necesarias tales normas jurídicas? ¿Por qué no nos quedamos simplemente con los principios morales que determinan el comportamiento a realizar?" ${ }^{21}$. La paradoja se presenta porque, al menos aparentemente, "para que las normas jurídicas sean operativas, para que provean o completen razones para actuar, es necesario recurrir a principios morales; pero esos principios indican por sí mismos cómo debemos conducirnos, lo que hace superfluas a las normas jurídicas"22.

Nino propone desarticular esta paradoja develando y examinando a fondo tres presupuestos o postulados a priori que considera implícitos en su misma formulación:

a) Que el individuo desea tomar en cuenta principios morales y actuar en consecuencia $^{23}$; y que la obligatoriedad del Derecho se justifica por su correspondencia con estos principios morales.

b) Que los principios morales son cognoscibles.

c) Que los principios morales regulan la conducta a modo de reglas. Esto es, ofreciendo una única solución para cada caso.

Si uno o varios de estos presupuestos fuesen falsos la paradoja quedaría, como consecuencia de ello, desmontada.

\footnotetext{
19 NiNo (1986) p. 115.

20 Nino (1986) p. 115.

21 Nino (1986) p. 115.

22 NinO (1986) pp. 115-116.

23 John Finnis define de un modo muy semejante al bien humano básico de la razonabilidad práctica. Desde esta perspectiva, no se trata de un presupuesto lógico sino axiológico, potencialmente justificatorio del Derecho. Cfr. Finnis (2000) pp. 131-163.
} 


\subsection{PRIMER PRESUPUeSTO: El INDIVIDUO DESEA TOMAR EN CUENTA PRINCIPIOS MORALES Y ACTUAR EN CONSECUENCIA}

Con relación al primer presupuesto, Nino advierte que si bien es cierto que hay hombres que no desean tomar en cuenta principios morales y actuar según ellos -y que por lo tanto a primera vista el presupuesto sería falso, y en consecuencia también lo sería la paradoja- el modo correcto de situarse frente al problema de la relevancia del gobierno y del Derecho es el del hombre moral, no el del inmoral. Y esto es así porque en la misma formulación de la pregunta por la relevancia moral del Derecho se presuponen o implican la convicción de que existen principios morales y el interés en ajustar la conducta a estos ${ }^{24}$. La perspectiva del "hombre moral", entonces, es la que interesa: es él, y no el inmoral, quien se pregunta por las razones que justifican al gobierno, a la democracia y al Derecho. Y desde preciso punto de vista es desde donde se afirma y parece tener sentido la superfluidad o irrelevancia del Derecho.

Ahora bien, la perspectiva del hombre moral no es solipsista. Nino sostiene que "si bien es cierto que, cuando nos preguntamos por la legitimidad moral del gobierno y de la democracia, debemos situarnos en la perspectiva del hombre moral, es errado suponer que para el hombre moral la única conducta que está en juego es la suya propia. Por supuesto, el hombre moral está también interesado en la conducta de sus congéneres. Es evidente que tiene que presuponer que muchos de ellos, por mala voluntad o por ignorancia, se comportarán inmoralmente, y es precisamente para incidir en el comportamiento de estos, que el hombre moral recurrirá al gobierno y a sus normas jurídicas, a quienes considerará moralmente justificadas en la medida en que las prescripciones dirigidas a los descarriados se ajusten a principios morales" 25 .

Si se asumiera esta descripción de la posición del hombre moral, la vía de justificación de la relevancia del Derecho -y por lo tanto de superación de la paradoja- estaría dada por la existencia evidente y notoria de algunos que tienen mala voluntad y de otros que son, desde el punto de vista moral, ignorantes. El Derecho estaría justificado, entonces, por su capacidad para evitar que la maldad y la ignorancia se apoderen de la sociedad.

El problema con esta solución es que a través de ella se podría llegar a justificar el monopolio de la coacción como la nota distintiva exclusiva del Derecho -el Derecho se propondría guiar la conducta de la gente ignorante o de mala voluntad-, pero no se justificaría en cambio su contenido normativo. No se justificaría, concretamente, que haya alguien que decida independientemente del hombre moral cómo deberían actuar los inmorales. Es decir, incluso en el caso de que el Derecho sirviese para guiar la conducta de los ignorantes y de los débiles, seguiría apareciendo como dificultad a resolver la de justificar que el hombre moral aceptase la imposición de determinadas conductas por parte de alguien distinto de él mismo. Desde este punto de vista, el hombre moral seguiría siendo "el «legis-

\footnotetext{
24 Sostiene el autor argentino: "por supuesto que hay mucha gente que no está motivada a actuar de acuerdo a principios morales, pero esa gente no se preocupa tampoco por la justificación del gobierno y por la justificación de la democracia; excepto por lo que hace a razones prudenciales, al hombre inmoral tanto le da que haya o no gobierno y que, de haberlo, este sea o no democrático”. Nino (1986) p. 119.

25 Nino (1986) pp. 119-120.
} 
lador supremo» no solo para sí mismo sino también para los demás", ya que lo que dispone quien ejerce la fuerza solo sería moralmente válido en la medida en que coincidiera con su propio juicio. En otras palabras, si el Derecho únicamente propusiera razones para la acción a los "protervos", por utilizar la conocida expresión tomista, su eficacia sería muy limitada. Este déficit se acentuaría aun más en un escenario como el actual, caracterizado por el pluralismo ético: como advierte Nino, todos los hombres morales, por diferentes que sean sus respectivas concepciones éticas, se sentirían con derecho a imponerlas a los demás y, agregamos nosotros, a desobedecer aquel Derecho que no se ajustara a su propio criterio $^{26}$.

Podría a este respecto replicarse que el hombre moral no condiciona la obligatoriedad del Derecho a un ajuste perfecto entre su moral y el Derecho, sino que tolera ciertas desviaciones inevitables, a fin de salvar la eficacia del Derecho en su función básica de encarrilar a los protervos o inmorales ${ }^{27}$. Con esta salvedad, entonces, una primera explicación de la relevancia del Derecho que remite al OMI consistiría en argüir que no pretende hacer una diferencia en el razonamiento moral de todo ciudadano sino, (a) de modo principal y general, en el razonamiento moral de los ciudadanos inmorales y, (b) secundariamente, en el razonamiento moral de los ciudadanos morales en los casos de desajuste leve con su conciencia. De este modo, el contexto de pluralismo o diversidad ética no condicionaría gravemente la eficacia del Derecho.

El problema con esta vía de solución es que se trataba de justificar la función regulatoria del Derecho frente al hombre moral, y no única ni principalmente frente al inmoral. El primer caso es el focal o más interesante. Sin embargo, en esta alternativa la existencia del gobierno y de las normas acaba siendo para el hombre moral un dato fáctico, que solo afecta a lo que Nino denomina "juicios morales derivados", pero no a los "principios morales últimos", que no se encuentran "condicionados por ninguna circunstancia fáctica”. Por otro lado, las consideraciones que conducen al hombre moral a justificar que los demás y en ocasiones él mismo deban obedecer leyes injustas "son de amplia aplicación pero de una importancia menor desde el punto de vista moral"28; esto último porque "ellas requieren que el gobierno coincida generalmente en las cuestiones más importantes para el juicio del hombre moral y están basadas en la circunstancia de que, si a la gente se la deja desobedecer las leyes cuando son injustas, lo hará también cuando sean justas"29.

En definitiva, concluye Nino que "el primer presupuesto de la paradoja es parcialmente cierto: debemos partir del punto de vista del hombre moral, quien recurre a principios morales para guiar su propia conducta y la de los demás, y para quien el Derecho es relevante para justificar esa conducta en la medida en que no estén en juego principios básicos, y en que los casos en que el Derecho se desvía de sus juicios morales sean más o menos importantes que los casos en que coincide, y es por lo tanto moralmente superfluo" 30 .

\footnotetext{
26 NinO (1986) p. 120.

27 Nino (1986) p. 120.

28 Nino (1986) p. 121.

29 Nino (1986) p. 121.

30 Nino (1986) pp. 121-122.
} 


\subsection{Segundo presupuesto: el individuo SABE lo QUe Disponen los PRincipios MORALES}

El segundo presupuesto al que se refiere Nino es el siguiente: subyace al argumento de la paradoja la afirmación de que el individuo sabe lo que disponen los principios morales. De modo paralelo a lo que ocurría en el caso anterior, si el individuo no supiera lo que disponen los principios morales, entonces el Derecho sería relevante, al menos para explicitarlos. Se trata de un presupuesto a primera vista falso: "es obvio que en muchos casos el individuo en cuestión está dispuesto a actuar y a juzgar a las acciones de los demás según principios morales pero no sabe cuáles son esos principios. En estas situaciones, el hombre moral puede acudir a las autoridades y a sus normas jurídicas en busca de orientación moral, de modo que en este caso el derecho no sería superfluo. Las autoridades jurídicas funcionarían como autoridades epistémicas, proveyendo razones para creer que está moralmente justificado actuar de cierto modo" ${ }^{31}$.

El problema aparente con esta solución es la cara opuesta del problema que planteaba la vía anterior: si bien desde esta perspectiva la ignorancia moral justificaría la función regulatoria del Derecho, no lograría justificar en cambio su carácter coactivo. En línea con esto último, advierte Nino: “¿por qué el hombre moral debería recurrir a una autoridad, cuyo rasgo distintivo es el cuasi monopolio de la coacción, en busca de sabiduría ética? ¿No debería acudir preferentemente a un filósofo o a un sacerdote para que le ilumine el camino moral?" 32 . La objeción mostraría, sostiene Nino, "que tampoco la falta de conocimiento ético es una buena razón para fundamentar la relevancia moral del gobierno y de sus normas" ${ }^{33}$. Aunque el autor rechaza inicialmente, por lo dicho, la inexistencia de este presupuesto, volverá sobre el tema luego, como veremos.

\subsection{TERCER PRESUPUESTO: LOS PRINCIPIOS MORALES SIEMPRE ESTIPULAN UNA SOLUCIÓN (Y NO VARIAS) \\ Quien defiende la paradoja presupone, en tercer lugar, que los principios morales} siempre estipulan una solución para cualquier situación en la que el individuo se encuentra, puesto que si estipulasen varias la relevancia del Derecho podría consistir en determinar cuál de esas soluciones es la correcta o conveniente.

En opinión de Nino, hay dos tipos de circunstancias que pueden explicar la inexistencia de soluciones morales unívocas para situaciones determinadas. "La primera está dada por la posibilidad de que haya empates morales"34; es decir, "casos en los que haya razones de igual peso para realizar una conducta y su opuesta" ${ }^{35}$. La segunda, por la existencia de casos de indiferencia moral, que Nino ejemplifica con el sentido de la circulación del tránsito. Sin embargo, afirma luego, "es sumamente difícil determinar qué tipo de razones para actuar provee el derecho en aquellos casos en que no hay razones morales subyacentes o

\footnotetext{
31 NinO (1986) p. 122.

32 Nino (1986) p. 122.

33 Nino (1986) p. 122.

34 Nino (1986) p. 123.

35 Nino (1986) p. 123.
} 
hay razones opuestas de igual peso" ${ }^{36}$. En su opinión, en definitiva, el derecho no es capaz "de fabricar razones que no preexistían o de jerarquizar tales razones" ${ }^{37}$, y, por eso, "resulta sumamente dudoso que el Derecho y el gobierno puedan resultar moralmente relevantes en aquellos casos en los que no hay una solución única en nuestro sistema moral”38.

\section{DOS PROPUESTAS DE RELECTURA}

\subsection{UNA RELECTURA DE LA EXISTENCIA Y LA COGNOSCIBLIDAD DEL OMI COMO FUNDAMENTO DE LA RELEVANCIA DEL DERECHO}

De los tres presupuestos que implica la pregunta por la relevancia del Derecho que remite a un OMI, Nino recepta el primero y reformula los dos segundos. En su opinión, por lo tanto, el examen de estos tres presupuestos deja en principio indemne al argumento de la paradoja de la irrelevancia.

Existen, sin embargo, dos presupuestos más, de índole metaética, que se encuentran subyacentes en la afirmación de que el gobierno y el derecho son irrelevantes para el hombre moral: "el primero es que hay un sistema moral independiente de las prácticas sociales involucradas en la constitución, reconocimiento y ejercicio del gobierno, de modo que el ciudadano moral, cuando recurre a él para justificar el gobierno o sus normas, puede llegar a conclusiones sobre lo que debe hacer sin tomar en cuenta aquellas prácticas"39. El segundo presupuesto "tiene una formulación semejante a la anterior pero se refiere al plano epistemológico y no al ontológico: consiste en asumir que se puede acceder cognitivamente a ese orden moral independiente de las prácticas sociales involucradas en la existencia del gobierno también en forma independiente de tales prácticas" ${ }^{30}$. Como veremos, el autor argentino afirmará la existencia del primer presupuesto pero negará la del segundo, para negar de este modo la validez de la paradoja de la irrelevancia.

Respecto del primer "presupuesto profundo", Nino concede que el Derecho remite a un OMI, que este OMI existe, y que más aun, si no existiera, el Derecho sería incapaz de ofrecer auténtica razones para la acción, pues su propia normatividad carecería de todo fundamento. Reconoce, sin embargo, que existen posiciones éticas y jurídicas que niegan la existencia del OMI, pero ni siquiera se molesta en discutir este punto con ellas, por la sencilla razón de que lo que originó su indagación fue justamente la búsqueda de razones morales aptas para fundamentar el gobierno y el Derecho. En otras palabras, la pregunta misma - por las razones morales que justifican el gobierno y el Derecho- asume implícitamente, por un lado, que el Derecho no se autojustifica por el solo hecho de estar constituido por un conjunto de prescripciones o por ser eficaz; y, por otro lado, la inaceptabilidad del nihilismo moral.

\footnotetext{
36 NinO (1986) p. 123.

37 Nino (1986) p. 124.

38 Nino (1986) p. 124.

39 Nino (1986) pp. 124-125.

40 Nino (1986) p. 125.
} 
Otras posiciones, que Nino engloba dentro del "subjetivismo social", confunden lo bueno con las preferencias mayoritarias. Si se siguiera esta línea, la remisión del Derecho a un OMI sería circular, puesto que el acceso al OMI dependería de las preferencias mayoritarias, que a su vez se construirían en el ejercicio de la democracia y se expresarían en el Derecho. Así, "el hombre moral no encontraría razones para justificar al gobierno que sean independientes de las decisiones de ese mismo gobierno y que las hiciera, por lo tanto, moralmente superfluas" ${ }^{41}$. Como bien sostiene Nino, el subjetivismo social es inaceptable; desde el punto de vista que proporciona el tema que aquí estamos estudiando, la objeción central es que "hace falsa por definición la posición de la minoría, y así no puede explicar el progreso moral (que se da cuando una posición minoritaria pasa a ser mayoritaria), consagrando el conservadorismo moral más absoluto" ${ }^{2}$.

Una tercera posición negatoria de la existencia del OMI es descripta por Nino como "una variedad más compleja y sutil del subjetivismo ético de índole social” 43 , "que a veces se identifica con un tipo de constructivismo ético y que sostiene que las razones morales se construyen a través del desarrollo del discurso moral”. Según esta postura, que Nino encuentra desplegada en el pensamiento de Habermas, "los principios morales válidos son aquellos a los que se arriba mediante un proceso de discusión sometida a ciertas restricciones formales" ${ }^{\prime 4}$. Si ese proceso de discusión se identificase con el que se da en el seno de la democracia, entonces no solo se justificaría la relevancia del gobierno y del Derecho, sino que se debería concluir que la democracia es la única forma de gobierno legítima. En otras palabras, "llegaríamos a la conclusión de que la democracia es la única forma de gobierno en que este no resulta superfluo para quienes se guían autónomamente por la moral, ya que solo la democracia incorpora al gobierno la discusión a través de la cual se constituye la moral” ${ }^{25}$.

Esta última posibilidad es atractiva para Nino, quien detecta y desarrolla la relación entre democracia y discurso moral. Como se verá, incorporará a su lectura del planteamiento de Habermas matices importantes - propondrá, como alternativa, un "constructivismo epistemológico" ${ }^{46}$-, provenientes en buena medida de su recepción de algunos de los planteamientos rawlsianos. Según su opinión, "el discurso o discusión moral es la práctica social dirigida a obtener consenso unánime acerca de ciertos principios que sirven de justificación última de acciones e instituciones. En muchos casos se obtiene ese consenso entre quienes pueden estar afectados por una medida o curso de acción y, de este modo, la práctica de la discusión cumple con su función social latente de evitar conflictos y facilitar la cooperación

\footnotetext{
41 NinO (1986) p. 125.

42 Nino (1986) p. 125.

43 NinO (1986) p. 125.

44 Nino (1986) p. 125.

45 NinO (1986) p. 125.

46 Nino (1986) p. 93 y ss. Explica Nino: "la defensa de este enfoque la haré contrastando el pensamiento de dos grandes filósofos: John Rawls y Jürgen Habermas. Sin embargo, creo que ninguno de ambos pensadores aciertan a formular exactamente esa posición. Como su leve alejamiento del blanco se produce en direcciones opuestas, el contraste entre Rawls y Habermas es sumamente ilustrativo pues permite inferir el curso teórico apropiado" (p. 93).
} 
entre individuos con intereses parcialmente divergentes" ${ }^{47}$. Sin embargo, en muchos otros casos, la discusión no alcanza efectividad "porque hay un momento relevante para adoptar la medida o curso de acción y en ese momento no se ha alcanzado el consenso unánime" 48 .

La salida de esta situación no puede alcanzarse insistiendo en el logro de un consenso unánime, puesto que hacerlo implicaría "favorecer al grupo, que bien puede ser minoritario, que está a favor del statu quo, de que no se adopte decisión alguna” ${ }^{49}$. Debe buscarse, por eso, otro camino. En opinión de NinO, concretamente, "hay que fijar una oportunidad relevante para la decisión y exigir lo que más se aproxima al consenso unánime que es la simple mayoría" ${ }^{50}$, y no una mayoría calificada, que daría poder de veto a una minoría ${ }^{51}$. Por este camino, la democracia es presentada como un "sucedáneo del discurso moral": "se trata de una forma regimentada de la discusión a la que hay que recurrir cuando esta discusión no es operativa. Mientras el discurso moral es un procedimiento de justicia procesal pura perfecta (...), ya que el único criterio de validez de sus resultados es que se hayan seguido sus reglas y estas aseguran esa validez, la democracia es un procedimiento de justicia procesal pura pero imperfecta, porque sus reglas implican algún apartamiento del procedimiento ideal” 52 .

El desenmascaramiento de este primer presupuesto profundo (es decir, metaético) permitiría la superación de la paradoja de la irrelevancia. Es decir, si no existiese un OMI independiente de la democracia, entonces la democracia y las normas serían relevantes. Según Nino, no obstante, la crítica de este primer presupuesto no puede ser aceptada tal como acabamos de exponerla. Es decir, según Nino sí existe, en alguna medida, un OMI. Y esto último es así porque en toda discusión moral se discute sobre la legitimidad de los intereses que defienden quienes discuten. Y la discusión sobre la legitimidad de los intereses implica, a su vez, "suponer que hay principios morales cuya validez es independiente del resultado de la misma discusión”. Desde este punto de vista, resulta "innegable que en el discurso moral se alude implícita o explícitamente a principios o teorías morales" 53 .

Por esto último, "una discusión moral profunda y esclarecida debe terminar versando acerca de qué principios morales básicos son válidos”. El criterio de validez que permite evaluar un principio es, en opinión de Nino, su aceptabilidad hipotética "por todos los que puedan estar afectados por ese principio (cualesquiera sean sus intereses, planes de vida o características personales) en condiciones de imparcialidad, racionalidad y conocimiento plenos". Siendo esto así, no queda otra salida que descartar una concepción de la ética "que ve a los principios morales como el resultado de la discusión real; en todo caso, los principios morales válidos son el resultado de un consenso ideal, al que se alude en esa discusión real”.

La distinción anterior se plasma, como conclusión, en un rechazo de lo que Nino denomina "constructivismo ontológico" y en la aceptación de un "constructivismo epistemológico". Esto le permite aceptar, al menos de modo implícito, la existencia de un OMI

\footnotetext{
47 Nino (1986) pp. 126-127.

48 Nino (1986) p. 127.

49 Nino (1986) p. 127.

50 Nino (1986) p. 127.

51 Cfr. Nino (1986) p. 127.

52 Nino (1986) p. 127.

53 Nino (1986) p. 128.
} 
(un "orden moral independiente"; es decir, la existencia de un orden moral independiente de toda práctica social), pero no la de un CMI (un "conocimiento moral independiente"; es decir, conduce a descartar que resulte factible acceder "a ese orden moral en forma individual y aislada, o sea, de modo independiente de toda práctica social" ${ }^{54}$ ). Nino asigna a la democracia valor epistemológico "como un método adecuado de conocimiento moral, ya que ella incluye esencialmente la discusión y el acuerdo mayoritario, que son formas de aproximarse a la verdad moral" 55 . Vale la pena mencionar que en una primera etapa de su pensamiento el autor argentino había optado por un "constructivismo ontológico" 56.

Con la destrucción del presupuesto CMI el autor pretende haber desarbolado también la paradoja de la irrelevancia. Empleando sus propias palabras: "a diferencia de lo que supusimos al comienzo, el presupuesto (ii) [que subyace al argumento de la paradoja la afirmación de que el individuo sabe lo que disponen los principios morales] es parcialmente falso como hipótesis general y su falsedad hace relevante la existencia de un gobierno siempre que este sea democrático: el hombre moral generalmente está en la situación de que si bien quiere actuar por razones morales, no está seguro acerca de cuáles son ellas. El proceso de discusión democrática, reflejado en las decisiones de las autoridades de ese origen, puede orientar al hombre moral hacia los principios morales válidos" ${ }^{57}$. El Derecho, por su parte, tiene la relevancia que deriva de su carácter de sucedáneo del discurso moral. Por el contrario, un gobierno no democrático (y las normas dictadas por él) no permitiría al hombre moral el acceso a ese orden moral válido, y respecto de él el argumento de la irrelevancia permanecería incólume.

\subsection{UnA RELECTURA DEL PRESUPUESTO DE LA NATURALEZA CONCLUYENTE DE LA MORAL COMO FUNDAMENTO DE LA RELEVANCIA DEL DERECHO}

\subsubsection{El Derecho como práctica colectiva: una segunda etapa del pensamiento de Nino}

Con razón apunta Nino que la pregunta por la relevancia del Derecho presupone que el OMI al cual remite el Derecho ofrece respuestas unívocas para cada caso. Si así no fuera, el Derecho estaría ahí para optar por una de entre las muchas respuestas correctas que ofrece el OMI para cada caso de coordinación social de la conducta. Si en cambio fuera cierto que la moral ofrece respuestas concluyentes, la relevancia del Derecho se limitaría a su capacidad para mostrar o hacer inteligible estas respuestas en el plano de la coordinación social. La relevancia del Derecho se comprendería, en fin, desde una relectura del segundo presupuesto o a priori de la pregunta por la relevancia del Derecho (el CMI).

Hasta aquí, entonces, la primera aproximación de Nino al problema de la paradoja: la relevancia del Derecho estaría justificada por su capacidad epistémica, es decir, por su capacidad de revelar cuál es el contenido del OMI con el que el Derecho se relaciona.

\footnotetext{
54 Nino (1986) p. 129.

55 Nino (1986) p. 131.

56 Cfr., al respecto, Ródenas (1991) pp. 279-293. La primera visión de Nino, en (1984) p. 241; la segunda, en (1989) pp. 393-398.

57 Nino (1986) pp. 131-132.
} 
En una segunda etapa, muy cercana a su muerte, Nino propuso en cambio una relectura del presupuesto según el cual la moral ofrece respuestas concluyentes para todos los casos (que había aceptado como verdadero en la etapa anterior). Nino no prentende ya afirmar que el Derecho determina lo que la moral deja abierto o irresuelto, o muestra o hace visible el OMI. Lo que el autor argentino sugiere en esta segunda aproximación es que el Derecho soluciona un tipo específico de problemas morales (los problemas de "moralidad social"), mediante una racionalidad específica, que sería parecida pero no igual a la racionalidad apropiada para resolver problemas morales "privados", y en esto radicaría su identidad o relevancia.

La opinión de Nino en esta segunda etapa es que la racionalidad del Derecho solo se comprende bien cuando se comprende también que el Derecho es una acción o práctica colectiva $^{58}$. Para desarrollar esta idea propone varias analogías. Se vale, sobre todo, de la comparación entre el trabajo del operador jurídico y la participación de un músico en un conjunto o una orquesta. Nino sostiene que un buen músico posee, obviamente, sus propios criterios acerca de cómo debe interpretarse un cuarteto o una sinfonía. "Sobre la base de esa valoración, el músico juzgará los méritos de la ejecución conjunta y, si su valoración difiere de la de los demás integrantes del conjunto, tratará de convencerlos para que ajusten la contribución de cada uno de ellos a la obra colectiva a los criterios que él defiende" "59. Si el músico no convenciera a sus compañeros, podrían ocurrir dos cosas: que decidiese no participar de la obra, o que, por el contrario, decidiese participar, sobre la base de que la ejecución tiene algún valor, aunque no coincida completamente con su gusto. Nino continúa diciendo que "al decidir esto, sería absurdo que el músico de nuestro ejemplo realizara su contribución según sus particulares valoraciones si ello produjera una falta de sintonía con la contribución de los otros músicos" ${ }^{\prime 0}$. Dicho con otras palabras, si al músico le interesara que su contribución fuese eficaz, debería ajustarla a las concepciones estéticas de los demás ${ }^{61}$. Por eso, sostiene Nino, "es necesario que tenga en cuenta el estilo que los otros músicos imprimen a su ejecución y que seguirán imprimiendo en el transcurso de la misma. Es posible que la obra le dé algún margen que le permita expresar, en su contribución, su propia concepción estética y aproximar así la ejecución conjunta a su ideal musical. Sin embargo, la expresión de su propia concepción se verá limitada por la necesidad de una ejecución armoniosa, en la medida en que juzgue que esa ejecución tiene algún valor, y que no tiene posibilidades reales de participar de una ejecución colectiva que se aproxime aún más a su propia concepción estética" ${ }^{62}$.

Del ejemplo surge, sigue diciendo Nino, "que hay una racionalidad específica al participar en obras colectivas. Cualesquiera que sean los criterios o modelos que definen lo que es óptimo en la clase de cosas o fenómenos a los que pertenece la obra colectiva, esos modelos o criterios resultan modificados cuando se aplican a una acción que contribuye a

58 Sin embargo, a diferencia de otros autores que compartirían esta afirmación, como por ejemplo Finnis, Nino no acaba de responder por qué esta práctica nos vincula. Por qué habría que obedecer esos criterios "colectivos" y no otros. La costumbre en sí misma no deja de ser un hecho.

59 Nino (1994) p. 135.

60 Nino (1994) p. 135.

${ }^{61}$ Cfr. Nino (1994) p. 135.

62 Nino (1994) p. 135. 
una obra sin tener el control absoluto sobre la misma" ${ }^{3}$. En este tipo o clase de acciones surge un nuevo modo de racionalidad, "puesto que, en tanto nuestra aportación a una obra colectiva es limitada y no controlamos el producto final, lo racional puede ser elegir, no el modelo o principio más defendible, sino otros con méritos menores. Este tipo de racionalidad, constreñida en la obra colectiva por las elecciones de los otros, podría ser denominada de «lo segundo mejor», puesto que, muchas veces, nos lleva a un alejamiento progresivo del modelo óptimo, en atención a sus efectos sobre la obra global" ${ }^{64}$.

Partiendo de este ejemplo y de esta conclusión, nuestro autor propone concebir la tarea del operador jurídico como una participación en una obra colectiva ${ }^{65}$. El objeto de esa obra colectiva - de la que participarían constituyentes, legisladores, jueces y administradores- "es el desarrollo del derecho vigente como parte de un proceso todavía más amplio, como lo es el complejo de prácticas, instituciones, costumbres, actitudes culturales y creencias básicas que definen a una sociedad" 66 .

\subsubsection{Un razonamiento jurídico en dos niveles}

Nino propone, entonces, reconocer "el hecho de que la acción de los legisladores y jueces se desarrolla en el contexto de una obra colectiva cuyos restantes aportes ellos no controlan" ${ }^{67}$. Este hecho es independiente de que un legislador o un juez consideren que el Derecho existente es tan deficiente que vale la pena refundarlo o incluso desobedecerlo. "Lo que simplemente toma en cuenta es la circunstancia de que, si la anterior no es una alternativa aceptable, la decisión del juez debe concebirse como parte integral de un orden jurídico, fundado en un cierto hecho constitucional" ${ }^{68}$.

Dicho de otro modo, lo que debe reconocerse es que "si la única forma de tomar decisiones moralmente justificadas ha de ser en el contexto de prácticas sociales existentes, se hace necesario preservar el orden jurídico vigente, salvo que sea tan injusto que no pueda ser mejorado y que la única decisión moralmente justificada es la que conduce a descono-

\footnotetext{
63 Nino (1994) p. 136.

64 NiNO (1994) p. 137.

65 La conexión entre esta idea y la conocida imagen de la "novela en cadena" que propuso el Prof. R. Dworkin es evidente. Aunque el estudio de este punto desborda el objeto que aquí nos hemos propuesto, conviene dejar constancia de lo que Nino señala al respecto. Según él mismo dice, su enfoque difiere del de Dworkin y de los de otros autores en que "solo parte del reconocimiento del hecho de que la acción de los legisladores y jueces se desarrolla en el contexto de una obra colectiva cuyos restantes aportes ellos no controlan. Este enfoque es perfectamente compatible con la conclusión de un juez o de un legislador acerca de que el derecho vigente hasta ese momento es tan precario, que vale la pena el esfuerzo de arriesgar una refundación, e incluso justifica, si ese esfuerzo fracasa o es imposible, una situación de anarquía o de disgregación del orden jurídico. Lo que simplemente toma en cuenta es la circunstancia de que, si la anterior no es una alternativa aceptable, la decisión del juez debe concebirse como parte integral de un orden jurídico, fundado en un cierto hecho constitucional” (idem, 138-139). La propuesta del Prof. Dworkin, en (1986a) pp. 146-166 y (1986b) pp. 228-238. En el primero de estos trabajos Dworkin dice, expresamente, que su concepción del sistema jurídico como un ejercicio de interpretación es "profunda y completamente política" (146). La bibliografía existente sobre esta propuesta es abrumadora. Puede cfr., al respecto, Zambrano (2007) pp. 281-326.

66 NinO (1994) p. 137.

67 NinO (1994) p. 138.

${ }^{68}$ Nino (1994) p. 139.
} 
cerlo, aun a riesgo de no poder establecer otro con éxito". El autor sostiene, a partir de las ideas precedentes, que el enfoque propuesto por él "revela que el razonamiento jurídico muestra una estructura escalonada en dos niveles" ${ }^{69}$ :

a) un nivel primario y básico, en el que "se deben articular las razones que legitiman o no la práctica social constituida por el derecho positivo"70. Rigen aquí "razones sustanciales y procedimentales que permiten ubicar a ese derecho en un continuo de legitimidad"71.

Volviendo a la analogía empleada párrafos más arriba, en este nivel se trataría de establecer si los criterios estéticos de la orquesta en su conjunto son en términos generales conciliables con los que tiene personalmente el músico, más allá de que puedan no coincidir por completo.

b) Una vez superado el primer nivel del razonamiento jurídico (es decir, una vez que se ha concluido que el orden jurídico es legítimo, incluso aunque pueda ser imperfecto), se pasa al segundo nivel en el que "se trata de aplicar ese orden jurídico para justificar acciones o decisiones". Este segundo nivel se desarrolla en el contexto proporcionado por el primero: "quedan excluidas las razones justificatorias (...) incompatibles con la preservación del derecho positivo (...) si es que aquel razonamiento ha arrojado como resultado que ella es más legítima que cualquier alternativa realista"72. Por esa razón, "un principio que tiene impecables credenciales desde el punto de vista de los criterios de validación implícitos en nuestro discurso moral puede ser, sin embargo, descalificado o exceptuado si ello resulta necesario para preservar la vigencia del sistema jurídico”. Retornando nuevamente a la analogía, si el músico ha encontrado en el primer nivel de razonamiento razones suficientes para tocar en esa orquesta concreta es posible que en el segundo nivel deba dejar de lado -al menos en alguna medida- su criterio estético personal en la interpretación concreta de la pieza que le toca.

Los principios de moralidad social influyen en los dos niveles. En el primer nivel actúan como "último tribunal de apelación". En el segundo adquieren una relevancia decisiva "en la medida en que no sean incompatibles con las conclusiones alcanzadas en el primer nivel". De lo contrario, señala Nino, "serían autofrustrantes, puesto que neutralizarían las conclusiones alcanzadas mediante su propio empleo"73.

Abordando el mismo tema desde un ángulo distinto, podría interpretarse que Nino se plantea dos preguntas fundamentales: a) ¿para qué el Derecho en general?; b) ¿por qué y para qué esta norma en relación con esta conducta o decisión en particular? La respuesta a la primera pregunta, desde esta perspectiva, condiciona la respuesta a la segunda. Se trata de un planteamiento en general acertado, que, por un lado, parte de la consideración del

\footnotetext{
${ }^{69}$ NinO (1994) p. 140.

70 Nino (1994) p. 140.

71 Nino (1994) p. 140.

${ }^{72}$ Nino (1994) p. 141.

73 Nino (1994) p. 141.
} 
Derecho como praxis y sobre esa base confiere primacía a su $\mathrm{fin}^{74}, \mathrm{y}$, por otro lado, permite (o es plenamente compatible con) centrar el razonamiento práctico jurídico correctamente, como un caso especial del razonamiento práctico, aunque Nino no llegue a hacerlo. Desde este último punto de vista se comprende mejor cuál es el límite y también el sentido del segundo nivel al que se refiere el profesor argentino. Como sostiene Orrego remitiendo a Alexy: "razonar prácticamente en el ámbito jurídico es dirigir el razonamiento hacia la finalidad práctica de hacer justicia conforme al Derecho, y no simplemente alcanzar la solución más justa posible simpliciter" 75 .

La descripción de un producto humano, y el Derecho lo es, no permite su explicación. Por ejemplo, la descripción de un reloj (¿en qué consiste?): una esfera, dos agujas que giran a distinta velocidad, etc., no permite su explicación (¿qué es un reloj?). Para poder dar cuenta de esto último es necesario preguntarse acerca de para qué fue producido. Del mismo modo, la sola descripción del fenómeno jurídico no permite, tampoco, explicarlo ni, mucho menos, comprenderlo. La comprensión solo puede alcanzarse, como ha señalado Sergio Cotta, sobre la base de la consideración de los fines últimos del Derecho como práctica: "cuando algo se produce, la primera indagación que cabe es la del fin que persigue el sujeto que lo produce. Tal es el fundamento de la llamada interpretación teleológica o finalista, capaz de aclararnos el hecho producido atendiendo al fin que se ha deseado (...). Sin duda, el Derecho (...) es un producto cultural humano, en la significación más simple y usual de producto: son los hombres quienes producen las leyes, sentencias, contratos, etc. Y los producen para servir una determinada finalidad abstracta y para aplicar a innumerables casos concretos"76. Esto y la conexión entre descripción, explicación y comprensión explica que, como afirma Dworkin, una respuesta acerca de cuáles son esos fines se encuentre al menos de modo implícito en toda participación en la práctica del Derecho ${ }^{77}$.

Sobre la base proporcionada por las ideas expuestas y con las limitaciones que se han insinuado (y que luego se explicitarán con mayor amplitud), Nino ofrece, entonces, su solución más acabada al problema de la relevancia del Derecho que remite a la moral.

\subsubsection{La superación de la paradoja de la irrelevancia en el razonamiento práctico}

Sostiene el autor argentino que "la concepción del Derecho positivo como una acción colectiva extendida en el tiempo a la que deben aplicarse los principios de justicia y de moralidad social, en lugar de aplicar directamente esos mismos principios a cada contribución a la práctica, permite (...) superar la paradoja de la irrelevancia del derecho positivo en el razonamiento práctico" 78 .

En efecto, "la referencia al derecho positivo resulta ineludible en el razonamiento práctico dirigido a justificar acciones y decisiones, ya que sin esa referencia la aplicación de

\footnotetext{
74 De LuCas (1982) pp. 121-125.

75 Orrego (2010) p. 317. Cfr., asimismo, Alexy (1997) pp. 274-275.

76 Cfr., al respecto, Coтta, (1987), pp. 21-22. Sobre este autor, cfr. Persona y Derecho 57 (2007), dedicado monográficamente a su figura y a su pensamiento.

77 Cfr. Ronald Dworkin, Law's Empire, op. cit., 31-44 y 65-68, entre otros lugares.

${ }^{78}$ Nino (1994) p. 145.
} 
los principios morales y de justicia tiene un objeto inapropiado. Los principios en cuestión tienen, como materia de valoración, prácticas sociales como el derecho positivo, y no la acción de un individuo aislado. Por lo tanto, el derecho positivo, aunque no provee razones últimas para justificar acciones o decisiones -que solo están provistas de aquellos principios aceptados autónomamente-, constituye el objeto de referencia de tales razones y una etapa intermedia obligatoria en el razonamiento práctico que conduce a una decisión"79.

Retornando a la analogía, en opinión de Nino el objeto de la práctica social en la que consiste el Derecho no es el ideal estético del músico del ejemplo -la moral o los principios morales-, sino los criterios estéticos con los que toca la banda -el Derecho positivo-. De allí que el profesor argentino sostenga que obviar el Derecho positivo supondría un error de objeto. El acierto de una decisión que se adopta en el contexto de una práctica colectiva no depende exclusivamente de la opinión de quien decide, sino también de los criterios y principios que surgen de ese contexto. Utilizando un conocido ejemplo de Dworkin: el intérprete que se pregunta acerca de si está ordenado o prohibido en una comunidad determinada ingresar a la iglesia con sombrero no puede prescindir en su respuesta de la praxis seguida hasta ese momento por los miembros de esa comunidad ${ }^{80}$. Esa praxis constituye, en realidad, el objeto concreto de su indagación. No lo es de modo inmediato, en cambio, su opinión personal acerca de la justicia o conveniencia de una norma de esa naturaleza. Dicho con otras palabras, según Nino, cuando el intérprete se pregunta ¿cómo debo resolver este caso?, en la misma pregunta está la referencia al Derecho positivo, pues es imposible ser justo sin atender al criterio de justicia que la sociedad ha acogido a través del él.

\subsubsection{Hacia la superación de la paradoja de la indeterminación radical del derecho positivo}

Esta paradoja es el resultado de la percepción del papel central que ocupan las valoraciones en el proceso de interpretación jurídica. Podría sintetizarse así: si la interpretación jurídica es radicalmente indeterminada, y su determinación solo puede hacerse recurriendo a la moral, ¿por qué el Derecho? ¿Por qué no, más bien, solo la moral?

¿Cuál es la respuesta que propone Nino? Según este autor, "una vez que reconocemos que el razonamiento jurídico presenta esta estructura escalonada, que la racionalidad correspondiente es del tipo de la segunda mejor posición y que los principios morales y de justicia no tienen por objeto acciones y decisiones individuales sino prácticas o acciones colectivas, entonces el Derecho ya no aparece como una caja negra asimilable, mediante cualquier solución, por nuestras valoraciones, sean las que sean, sino como una práctica que incluye criterios convencionales de interpretación de textos y otros materiales jurídicos relevantes. Esto implica mostrar que la paradoja de la indeterminación radical del Derecho solo se da cuando concebimos los actos y decisiones jurídicos como si fueran actos y decisiones aislados" 81 .

\footnotetext{
79 Nino (1994) p. 145.

${ }^{80}$ El ejemplo, aunque aplicado a otro problema, en DworkIN, Ronald (1977): Taking Rights Seriously (Duckworth, London), cap. 2.

${ }^{81}$ Nino (1994) p. 147.
} 
Aunque Nino no lo dice con estas palabras, lo cierto es que su propuesta consiste, en última instancia, en afirmar que la indeterminación jurídica no es "radical". Es decir, que no cualquier interpretación jurídica es aceptable, y que la aceptabilidad de una interpretación depende del Derecho positivo y no de la moral, puesto que no se trata de una acción individual llevada adelante por un intérprete concreto, sino una práctica colectiva.

\subsection{RECAPITULACIÓN}

Volvamos al inicio. Nuestra cultura de derechos manifiesta una conexión del Derecho con un OMI de la propia práctica jurídica; por ejemplo, a través del lenguaje de "reconocimiento", de la dimensión difusiva de los principios de los principios constitucionales sobre el resto del ordenamiento jurídico (la tesis alexyana de la incorporación), de la presencia del principio proporcionalidad de las leyes y de razonabilidad de la interpretación, y de la relación entre derechos fundamentales constitucionales y convencionales. La conexión entre Derecho y OMI podría sintetizarse en la doble aserción de que: a) la cadena de normatividad jurídica (validez y obligatoriedad) no se justifica a sí misma ni se remonta al infinito -lo cual sería tanto como afirmar que no se justifica en absoluto-, sino que se justifica por su referencia a un OMI; y b) la interpretación o determinación del sentido del Derecho no es autosuficiente, sino que implica la referencia a un OMI.

Esta doble aserción plantea el problema de la relevancia del Derecho en el razonamiento práctico, en su triple función de guiar, juzgar e interpretar el obrar. Si para decidir cómo actuar (guiar el obrar), o para justificar lo hecho (juzgar el obrar) y antes comprenderlo (interpretarlo) debo recurrir siempre a un OMI ¿cuál es la función específica del Derecho?

De los trabajos sucesivos que dedicó Nino a esta pregunta se sigue una solución en dos niveles, el cognitivo y el material. Son dos niveles que, bien miradas las cosas, se condicionan y presuponen mutuamente. Desde el punto de vista cognitivo Nino dirá que en la medida en que el Derecho se genera mediante un procedimiento de decisión democrático, asegura el acceso más fidedigno posible a lo justo según criterios del OMI. El Derecho democrático es pues una vía de conocimiento del OMI. Desde el punto de vista material, agrega este autor, el Derecho está ahí para solucionar no cualquier problema moral, sino los problemas morales propios de la interacción social dentro de una práctica colectiva. Este tipo de problemas admite distintos tipos de soluciones, algunas mejores que otras según los principios de moralidad social y de justicia. Sin embargo, la racionalidad moral propia o específica de las prácticas sociales obliga a trocar la mejor solución absolutamente considerada según una comprensión personal del OMI, por la mejor solución dentro de las que son compatibles con la comprensión que hace del OMI la práctica en su conjunto.

De forma que, como ya se ha dicho, de los tres presupuestos inicialmente implicados en la pregunta por la relevancia del Derecho, Nino en su segunda etapa reformula dos y mantiene uno. Mantiene la afirmación de la existencia de un OMI. Reformula el presupuesto de que este OMI es cognoscible o accesible de forma individual (CMI), y el presupuesto de que el OMI ofrece respuestas concluyentes para todos los casos. Sobre lo primero, el autor argentino dirá que el OMI no es objeto de un CMI en lo que respecta a problemas de coordinación dentro de una práctica colectiva, donde el proceso democrático es la vía más fiel de conocimiento. Sobre lo segundo dirá que el OMI no ofrece respuestas 
últimas para la coordinación dentro de las prácticas colectivas. El OMI es, en todo caso, la fuente a partir de la cual la práctica colectiva construye soluciones a sus problemas de coordinación, mediante un proceso de decisión colectiva propio.

Si se unen una y otra relectura de los presupuestos de la pregunta por la relevancia, se advierte que en realidad la respuesta es única: el Derecho no se conecta con toda la moral, de la cual a la vez se distingue. Se conecta porque el Derecho no construye soluciones desde el puro arbitrio, sino en un intento consciente por ser fiel al OMI. Se distingue porque esta búsqueda de fidelidad al OMI se realiza mediante un proceso de conocimiento y decisión colectivo, que postula o exige fidelidad a este mismo proceso y a sus productos.

En otras palabras, el Derecho es algo así como el proceso de conocimiento del OMI que, en principio y salvo que su apartamiento del OMI sea irremediable, exige fidelidad a determinaciones anteriores acerca de lo que el OMI exige en cada caso. Una vez que el Derecho ha definido mediante el proceso democrático que el OMI obliga a resolver un asunto Y de forma X, el partícipe del Derecho está obligado a continuar resolviendo otros asuntos análogos a $\mathrm{Y}$ de forma $\mathrm{X}$, aun cuando tenga conciencia plena de que $\mathrm{X}$ no es la mejor lectura del OMI. Ello es así por dos razones. Primero, porque el proceso democrático es el camino más fiel de acceso al OMI (relectura del presupuesto del CMI), de modo que debería permitirse dudar de su propia conciencia. Segundo, porque el Derecho es una práctica colectiva, cuya racionalidad específica exige fidelidad al conjunto de decisiones que han sido tomadas por otros actores de la misma práctica; es aquí donde radica su objeto propio (relectura de la naturaleza concluyente de la moral).

Según esto, la referencia de sentido y de justificación normativa de la cultura de derechos a un OMI no implica la confusión material entre uno y otro orden normativo y axiológico, ni la sustitución del Derecho por el OMI en el razonamiento moral de los partícipes del Derecho. Cuando los textos hablan de "reconocer derechos", no delegan este reconocimiento sin más a los particulares, sino a los procesos democráticos de decisión ordinarios y/o constitucionales, que son los que más garantías ofrecen de un CMI adecuado. Tampoco se delega al criterio de actores particulares la incorporación de principios en las prácticas constitucionales (a), sino al proceso democrático o, en su caso, al criterio de la judicatura, que está a su vez legitimada por el proceso democrático que lo invistió de autoridad en la instancia constitucional. Lo mismo cabe argüir respeto del criterio de razonabilidad (b) con el cual se juzga la validez de la decisión judicial, o el criterio de proporcionalidad (c) que condiciona la validez constitucional de la creación legislativa.

En los tres casos (a, b, c) la legitimidad de los derechos "reconocidos" se encuentra sujeta a la doble condición de que (i) hayan sido develados o abstraídos a partir del OMI mediante un proceso democrático, y (ii) de que cada nueva determinación democrática acerca de los principios de moralidad social y de justicia que integran el OMI se ajuste materialmente al conjunto de las determinaciones democráticas que componen la práctica jurídica en su totalidad.

La propuesta de Nino constituye, pues, un intento refinado de preservar, simultáneamente, la conexión entre el Derecho y el OMI, indispensable en su opinión tanto para justificar el carácter obligatorio del Derecho como para interpretarlo, por un lado, y la relevancia del Derecho, amenazada por la presencia y la función del OMI, por otro. Veremos a continuación, en las páginas siguientes, hasta qué punto ese intento alcanza la finalidad perseguida. 


\section{DE KELSEN A NINO Y DE NINO A KELSEN OTRA VEZ. LA PERSISTENCIA DE LA ENCRUCIJADA ENTRE EL REGRESO AL INFINITO, LA CIRCULARIDAD O LA FALACIA NATURALISTA}

Quien, como Nino, se pregunte por la relevancia del Derecho como razón para la acción, se sitúa en la senda de Hart y asume que el Derecho tiene la pretensión de guiar la acción con autoridad moral, esto es, generando un vínculo de obligatoriedad moral entre la norma y sus destinatarios. Asume, en otras palabras, que el Derecho proporciona o al menos pretende proporcionar auténticas razones para actuar, y no meramente motivos de interés.

Ahora bien, Nino advierte con toda lucidez que un Derecho de fuente exclusivamente social del tipo ideado por Kelsen carece de credenciales lógicas para generar obligaciones morales o, de modo más preciso, obligaciones categóricas. Derivar la obligatoriedad moral (que es un modo de normatividad) del Derecho a partir del hecho de su creación social, o a partir de la forma en que fue creado, es uno de los modos típicos de la falacia naturalista. Salvo, por supuesto, que se asuma la existencia de una norma que obliga moralmente a obedecer el Derecho creado por la sociedad. Pero entonces la pregunta por las credenciales lógicas para obligar se dirigiría a esta otra norma secundaria, por utilizar la terminología hartiana, que no podría ser a su vez de fuente social, o al menos se debería derivar en algún punto de una norma que no tuviera esa fuente, porque de lo contrario se produciría una regresión al infinito y cada uno de los eslabones de la cadena carecería de obligatoriedad.

De modo que, o bien la obligatoriedad moral del Derecho es recibida o participada desde alguna norma moral que obliga a obedecer el Derecho y que, a su vez, no se deriva de ninguna otra norma, o bien se trata de una aserción falaz. Ya se ha visto que Nino no tiene reparo alguno a afirmar esta disyuntiva y en señalar que el único modo de sortear la falacia naturalista y el regreso al infinito es afirmando algún vínculo de derivación entre el Derecho y un OMI originario, que no se deriva a su vez de otras normas morales o jurídicas. Con esta solución Nino parece distinguirse tanto de la tradición del realismo escandinavo como de la kelseniana. Pero cabe preguntarse en lo que sigue si esta distinción no es más que una genuina expresión de deseos.

El realismo escandinavo, fiel hasta el extremo a su escepticismo ético y a su programa de lograr que la ciencia jurídica fuera "reconocida como una ciencia social empírica" optó por negar el estatuto científico del problema de la obligatoriedad y reemplazarlo por el de verificación ${ }^{83}$. Según Ross, "el contenido real de las proposiciones de la ciencia del Derecho se refiere a las acciones de los tribunales bajo ciertas condiciones" ${ }^{84}$. Esto equivale, en el fondo, a negar la obligatoriedad del Derecho, o a reemplazarla, como pareciera hacer Ross, por la motivación o el interés, y a definir buena parte del lenguaje jurídico -aquella transida de moralidad (por ejemplo, los vocablos deber, obligación, norma, etc.)- como

82 Ross (1997) p. 66.

83 Según Ross, con vistas a lograr que el principio de verificación se aplique también en la ciencia del Derecho, "no debemos interpretar las proposiciones acerca del derecho vigente como proposiciones que aluden a una validez inobservable o «fuerza obligatoria» derivada de principios o postulados a priori, sino como proposiciones que se refieren a hechos sociales". Ross (1997) p. 66.

84 Ross (1997) p. 67. 
máscara de esa motivación o ese interés. Olivecrona, en la misma línea que Ross, no considera que el problema de la obligatoriedad pueda recibir tratamiento científico ${ }^{85}$. Sí puede tratarse científicamente, en cambio, la "fuerza vinculante", cuyo referente es la sensación de sujeción que producen las normas "como consecuencia de una serie de hábitos y condicionamientos psicológicos" $"$. Según sus propias palabras, "todo intento de mantener científicamente que el Derecho es obligatorio en otro sentido que el de ejercer de modo efectivo una presión en la población, necesariamente conduce a absurdos y contradicciones. Aquí, por lo tanto, está la línea divisoria entre realismo y metafísica, entre método científico y misticismo en la explicación del Derecho. La «fuerza obligatoria» del Derecho es una realidad como una idea en las mentes humanas. No hay nada en el mundo exterior que se corresponda con esta idea" ${ }^{87}$. Desde la curiosa, aunque no por eso menos actual, perspectiva del profesor de Lund, el Derecho se reduce a "fuerza organizada".

En un intento consciente y deliberado de distinguirse a la vez de la tradición del derecho natural y del desencanto del realismo escandinavo, Kelsen optó por renunciar a la obligatoriedad moral del Derecho y la trocó por una obligatoriedad puramente jurídica de difícil comprensión ${ }^{88}$. El debate de Kelsen con los escandinavos tiene mucho, en este sentido, del debate de Kant con el escéptico Hume. Al igual que Kant se propuso contra el utilitarismo de Hume afirmar la naturaleza categórica, no hipotética, de la moral, Kelsen afirma contra el realismo escandinavo que el Derecho es un orden normativo, y no en cambio un orden de intereses disfrazado de normatividad ${ }^{89}$. El Derecho es para Kelsen una regulación normativa de la conducta humana. Si se quiere es también o más propiamente una regulación del uso de la fuerza. Pero no es fuerza pura ${ }^{90}$.

85 Cfr. Olivecrona (1939) p. 9; y (1971): cap. VI, ep. V 1. Sobre este autor y la evolución de su pensamiento respecto de la obligatoriedad entre una y otra edición de su libro central, cfr. VerGara LaCALle (2004) pp. 259-286.

86 Vergara lacalle (2004) p. 250.

87 Olivecrona (1939) p. 17.

88 Sostiene este autor: "el principio de que el hombre debe cumplir siempre sus «obligaciones» o su «deber», claramente presupone que existen deberes absolutos, evidentes para cada cual. Por el otro lado, es decir, si se acepta que no hay una moral absoluta, sino varios órdenes morales, muy diferentes, que ordenan conductas entre sí contradictorias, la frase mencionada, que constituye la proposición fundamental de la ética kantiana, se diluiría en la tautología de que el hombre debe hacer siempre aquello que está ordenando según la moral al caso, es decir, que debe hacer lo que debe hacer. El concepto de obligación jurídica se refiere exclusivamente a un orden jurídico positivo, y no tiene ninguna implicación moral”. KELSEN (1960). Se cita de la ed. en español: (1982) p. 131.

89 Kelsen (1982) pp. 44-70.

90 Quizá por eso, Kelsen admite que el Derecho, entendido como orden jurídico positivo, debe ser evaluado moralmente aunque no exista un patrón moral objetivo. Le interesa destacar, en línea con esto último, que proponer, como él hace, el relativismo moral, no equivale a negar la existencia de patrones morales. Según sus propias palabras, "una doctrina relativista de los valores no significa -como múltiples veces ha sido mal entendido- que no haya valores y, en especial, que no exista justicia alguna, sino que no haya valores absolutos, sino solo relativos; que no hay una justicia absoluta, sino relativa; que los valores que constituimos mediante actos productores de normas, y que son fundamentos de nuestros juicios axiológicos, no pueden darse con la pretensión de eliminar la posibilidad de valores contrapuestos". Y enfatiza de inmediato: "es evidente que una moral puramente relativa no puede cumplir la función, consciente o inconscientemente, requerida de proveer de un patrón absoluto para la evaluación de un orden jurídico positivo. Pero patrón semejante no cabe encontrarlo en el camino del conocimiento científico. Ello no significa, empero, que no exista patrón alguno. Cada sistema moral puede servir como patrón semejante". KELSEN (1982) p. 80. 
Ahora bien, ¿cuál es la diferencia entre el uso de la fuerza sin más, y el uso reglado de la fuerza? ¿Cuál es la diferencia entre la orden del ladrón y la norma (jurídica)? Según Kelsen, la diferencia no debe buscarse en su sentido subjetivo (en ambos casos es una voluntad dirigida a la conducta de otro, que además incluye una amenaza), sino en su sentido objetivo: "damos a la orden del órgano jurídico, pero no a la del ladrón de carreteras, el sentido objetivo de una norma obligatoria para el receptor. Es decir, interpretamos la orden de uno, pero no la del otro, como una norma objetivamente válida. Y entonces vemos en el enlace del incumplimiento de la orden con el acto coactivo, en un caso, una mera "amenaza», es decir, la enunciación de que será infligido un mal, mientras que en el otro caso, la relación apunta a que debería infligirse un mal"'

La distinción entre la amenaza del uso la fuerza y el deber del uso de la fuerza, radica pues en la existencia o inexistencia de una norma jurídica válida que lo autorice o, más aun, que lo mande. La pregunta siguiente es cuál es el criterio de validez de la norma que autoriza o que manda a usar la fuerza, a lo cual Kelsen responde con su inserción en la clásica pirámide normativa: una norma es válida cuando ha sido producida según el criterio de producción establecido en otra norma válida, la cual a su vez será válida si fue creada según el criterio de producción establecido por otra norma, y así hasta la norma hipotética fundamental ${ }^{92}$.

La necesidad de hacer descansar la pirámide normativa completa en alguna norma es de orden lógico. Se trata de escapar a la recién mencionada y tan temida "falacia naturalista”, consistente en derivar normas a partir hechos. Solo si al final de la pirámide hay una norma puede Kelsen sortear este obstáculo y distinguirse, desde su perpectiva, tanto del iusnaturalismo como del realismo. Por su parte, la necesidad de que la norma que acepta situar al final de la pirámide sea hipotética es también, si se quiere, una necesidad lógica del postulado epistémico según el cual la positividad es la única garantía de racionalidad de cualquier orden normativo. Dicho más llanamente, el postulado según el cual las únicas normas racionalmente cognoscibles son las normas de fuente social ${ }^{93}$.

En efecto, si se sigue el camino marcado por este postulado epistémico hasta sus últimas consecuencias, habría que concluir que la norma fundante de la pirámide normativa debería ser positiva. Pero entonces habríamos vuelto a la aserción falaz, según la cual la obligatoriedad del Derecho emana de una norma que en sí misma no tiene otra justificación que el solo hecho de haber sido creada socialmente. La respuesta de Kelsen en esta disyuntiva es bien clara y conocida: "la norma jurídica que constituye el fundamento último de la validez (...), de manera alguna ha sido establecida por un acto de voluntad, sino que está presupuesta en el pensamiento jurídico"94. En la medida en que la norma hipotética está presupuesta, no sería pues asimilable a un hecho. Es, más bien, un a priori o una condición lógica de la normatividad del Derecho. En la misma medida en que el Derecho

\footnotetext{
91 Kelsen (1982) p. 58.

92 KeLSEN (1982) pp. 44 y ss.

93 Kelsen (1982) p. 75. Sostiene allí Kelsen: "la moral, como el derecho, es positiva, y para una ética científica solo entra en consideración una moral positiva, así como solo es relevante, para una doctrina jurídica científica, un derecho positivo".

94 KeLsen (1982) p. 36.
} 
es un sistema normativo, asume la existencia de una norma que obliga a obedecer la Constitución, y que a su vez no se deriva de ninguna otra norma.

Ahora bien, Kelsen no afirma que todo Derecho presuponga la existencia de una norma hipotética universal. Se limita a señalar en cambio que las normas producidas en cada práctica jurídica son obligatorias en tanto y en cuanto su particular Constitución mantenga su vigencia o eficacia, En este sentido, la naturaleza hipotética de la norma fundamental no es solo ontológica - existe como presupuesto lógico-, sino también práctica en el sentido más kantiano del término: obliga condicionalmente, y no categóricamente. La norma hipotética no manda u obliga a obedecer al Derecho de forma categórica, sino de modo hipotético o condicional a que se mantenga vigente ${ }^{95}$, lo que indudablemente resulta problemático, porque acaba vinculando la obligatoriedad con la vigencia (es decir, con un hecho), a través del puente que proporciona aquello que se presupone (la norma hipotética) ${ }^{96}$.

Esta condicionalidad explica que el Derecho no movilice a obrar mediante razones sino que se limite a ofrecer motivos para temer: "el Derecho (...) trata de producir determinada conducta humana, en cuanto enlaza a la conducta opuesta un acto coactivo socialmente organizado; mientras que la moral es un orden social que no estatuye sanciones de ese tipo"97.

En estos términos, para Kelsen la cadena de validez normativa no se distingue de la cadena de obligatoriedad. Cada cadena de normatividad en su totalidad (cada sistema jurídico), con sus dos caras de validez y obligatoriedad, presupone una norma última que obliga a actuar conforme a Derecho. Una norma que en sí misma no existe, sino que está asumida o presupuesta en la aserción de la validez de normas que sí existen o fueron creadas por fuentes sociales. La doble naturaleza hipotética de la norma fundante, ontológica y práctica, es a su vez la razón lógica de la no obligatoriedad moral del Derecho. El Derecho es obligatorio, pero no toma prestada su obligatoriedad de ningún orden moral. Su obligatoriedad es puramente jurídica y, en cuanto tal, diríamos nosotros, no es propiamente obligatoriedad sino más bien un motivo relativamente sofisticado: la pura conveniencia.

Nino, en cambio, no está dispuesto a contentarse con un Derecho que solo ofrece motivaciones hipotéticas para actuar, sujetas a la condición de que no exista un interés por contrariar la norma de mayor peso que el interés por evadir la sanción jurídica. Como se dijo, el profesor argentino se sitúa en la senda de Hart y proclama la obligatoriedad moral del Derecho aceptando lo que Kelsen no estaba dispuesto a aceptar, esto es, que el Derecho se conecta con un OMI.

El problema es que no parece haber sido del todo consciente, como sí lo fue Kelsen, del nivel de independencia que debería tener el OMI para que sirva de auténtico fundamento de la obligatoriedad moral del Derecho. En primer lugar, no debería tratarse meramente de un orden moral independiente del Derecho, sino de un orden moral independiente de toda praxis social. En segundo lugar, la independencia entre el orden moral y el jurídico no debería ser meramente formal, sino también y esencialmente material.

95 KeLsen (1982) p. 59.

96 A esta inconsecuencia se refiere Ross cuando afirma que "la norma básica esta desprovista de todo matiz ético. Se acomoda al orden que está de hecho en vigor y no es más que un postulado en el sentido de que este orden posee validez" -Ross (1997) p. 95-.

97 Kelsen (1982) p. 75. 
Sobre lo primero, la independencia del OMI respecto del Derecho no permite eludir el regreso al infinito en la justificación de la normatividad, pues todavía es preciso justificar la exigibilidad u obligatoriedad de este OMI. El único modo de cortar el regreso al infinito es aceptando que la independencia del OMI no es solamente independencia respecto del Derecho, sino respecto de toda otra instancia normativa. Lo cual es tanto como decir que el OMI contiene en su estructura normas morales que son intrínsecamente razonables, y cuya normatividad no está tomada de ninguna otra norma ni, mucho menos, de un hecho (ni siquiera del hecho de que el OMI haya sido receptado o incorporado a la práctica jurídica).

Es cierto que Nino, luego de algunas dudas iniciales, rechazó explícitamente lo que él dominó un constructivismo ontológico como fundamento adecuado para la obligatoriedad del Derecho, y optó en cambio por el denominado constructivismo epistemológico. Es cierto también que lo que rechazó del constructivismo ontológico es precisamente su capacidad para generar auténticas razones para obrar y, por lo mismo, para fundar la obligatoriedad de ningún orden normativo. En este sentido, parece que Nino también pensó en un OMI de toda praxis humana como fundamento de la normatividad del Derecho. En esta línea interpretativa, Nino afirma con insistencia que la democracia no es el discurso moral (si esto ocurriese, estaríamos ante un constructivismo ontológico). Es solo su sucedáneo. Por eso existe la posibilidad de que las normas producidas por la democracia no sean moralmente válidas, y por eso también parece que queda a salvo la naturaleza fundamental o no derivada del OMI.

Sin embargo, la radicalidad y exclusividad del constructivismo epistemológico que propone acaba por erosionar sus diferencias más significativas con el constructivismo ontológico. Nino descansa sobre algo así como una confianza dogmática en que el proceso democrático expresará y al mismo tiempo incorporará valores de justicia y que, además, es el modo más fiel de expresión de estos valores. Pero entonces, ¿cómo es posible conocer si las normas democráticas expresan genuinamente los valores de justicia del OMI, siendo la democracia, como este autor propone, el único sucedáneo fiel del discurso moral?

La dependencia epistemológica del OMI respecto del Derecho producido democráticamente le quita toda relevancia práctica, no ya al Derecho, sino a la misma moral. El OMI acaba siendo un mero postulado lógico difícilmente distinguible de la norma hipotética fundamental de Kelsen. Para Kelsen la norma hipotética fundamental no existe de forma independiente del Derecho. La norma hipotética fundamental es un presupuesto lógico del Derecho vigente y, más concretamente, de la naturaleza normativa del Derecho vigente. En la medida en que el Derecho vigente es un orden de normas, asume o presupone la existencia de una norma última fundamental que obliga a obrar conforme a Derecho.

Para Nino, en cambio, el OMI es un orden normativo independiente del Derecho. ¿Pero cuán independiente del Derecho es un orden que tiene como único vehículo de expresión al mismo Derecho que pretende fundar? ¿No acaba reduciéndose esta independencia, al fin y al cabo, a una mera necesidad lógica, la misma necesidad lógica que lleva a Kelsen a sostener la existencia de la norma hipotética fundamental?

Nino advertía, como Kelsen, que la cadena total de normatividad en su doble vertiente de obligatoriedad y validez se esfuma si se remonta al infinito o si se deriva de un hecho. De ahí la insistente y explícita aceptación de que el Derecho incorpora las exigencias 
de un OMI. Pero más allá de esta entusiasta aserción de conexión entre el Derecho y un OMI, y de la independencia del segundo, no parece que Nino haya avanzado mucho más que Kelsen, desde el momento en que se rinde a su propio escepticismo y no admite otro contenido para el OMI distinto de aquel al que se accede mediante el Derecho (lo que es tanto como decir el Derecho mismo).

En síntesis, la independencia que postula Nino es tan hipotética como la existencia de la norma fundamental en Kelsen. Es una necesidad lógica de la afirmación de la obligatoriedad moral del Derecho. Quizá podría concluirse que Nino y Kelsen han salvado la normatividad del Derecho de la falacia naturalista y del regreso al infinito, pero no la han salvado en cambio de la circularidad. En efecto, al mismo tiempo que el OMI y la norma hipotética fundamental sustentan como causa última la cadena de normatividad del Derecho, uno y otra deben su inteligibilidad -en el caso del OMI- o su existencia -en el caso de la norma hipotética fundamental- al mismo Derecho que se proponen fundar.

Esta circularidad se manifiesta no ya en una llana incapacidad del Derecho para diferenciarse de la moral (como guía para la acción), sino también en la incapacidad de la moral para diferenciarse del Derecho. Y la disolución de la moral en el Derecho, claro está, es bastante más peligrosa que la disolución del Derecho en la moral. No es extraño en este sentido que Nino acabe admitiendo que "salvo error, en los países democráticos es probable que sea obligatorio obrar conforme a Derecho" ${ }^{\text {, }}$ y que exija "que, a efectos prácticos, se tome esa probabilidad como certeza a la hora de actuar. Apelando al principio de que se deben maximizar las posibilidades de obrar de forma moralmente correcta, Nino cree que el discurso democrático -incluso imperfecto- justifica y aun exige relegar el propio juicio y acatar la norma"99.

Las normas jurídicas son, desde esta perspectiva que sostiene Nino, "razones excluyentes" según la caracterización de Raz, aunque el autor argentino se preocupa por no caracterizarlas así: en su opinión, las normas jurídicas son, en realidad, "razones epistémicas". Es decir, razones para creer que existen razones para actuar. Con esto busca preservar la autonomía de la moral (que se vería cuestionada, en su opinión, si existiesen autoridades prácticas), y, de modo simultáneo, huir del positivismo ideológico (en el que se incurriría si se definiese a las normas, sin más, como razones excluyentes) sin dejar de afirmar la obligatoriedad del derecho positivo ${ }^{100}$.

Esto último tiene, a su vez, al menos dos dificultades. La primera es la siguiente: "si se entiende que para el constructivismo epistemológico las normas democráticas actúan como razones excluyentes, la autonomía, presupuesto del discurso moral, queda en entredicho, ya que los destinatarios de las normas jurídicas siempre habrán de relegar su juicio, adoptando la norma como única guía de actuación. Si, por el contrario, se admite con Nino que son razones epistémicas (...), cuando se afirma que un sujeto ha llegado por reflexión individual al convencimiento de que las normas democráticas presentan errores morales relevantes y a la vez se le exige que «crea en la existencia de razones morales a favor

\footnotetext{
98 Kelsen (1982) p. 151.

99 Kelsen (1982) p. 152.

${ }^{100}$ Kelsen (1982) p. 152.
} 
de esas normas»", se le está pidiendo en realidad que acepte simultáneamente dos criterios de corrección, sin ofrecerle ningún argumento definitivo para primar uno sobre otro" ${ }^{101}$.

En definitiva, como afirma Blanco, la propuesta de Nino acaba teniendo un cierto aire de familia con el positivismo ideológico, pese a sus declaraciones de intentar un resultado exactamente contrario ${ }^{102}$.

\section{DE DWORKIN A NINO Y DE NINO A DWORKIN OTRA VEZ. LA PERSISTENCIA DE LA CIRCULARIDAD TAUTOLÓGICA EN LA INTERPRETACIÓN DEL DERECHO}

$\mathrm{Al}$ exigir que toda decisión judicial sea razonable (tanto en el plano fáctico como en el normativo) ${ }^{103}$, la cultura de derechos asume implícitamente que la creatividad interpretativa es inevitable. Si la creatividad fuera evitable, la exigencia no sería de razonabilidad sino de estricta fidelidad al Derecho (en el sentido de fidelidad al texto de la ley). Por otra parte, la exigencia de razonabilidad manifiesta, al menos, otros dos postulados a priori de la cultura de derechos. El primero es que el espacio de creatividad no es un espacio para la arbitrariedad ni la discreción irrestricta. El segundo, conectado con el anterior, es que el criterio para juzgar la legitimidad y validez de las elecciones interpretativas se da en su correspondencia con un OMI.

El primer problema con estas tres asunciones -creatividad, proscripción de arbitrariedad, conexión con un OMI como criterio de razonabilidad- es el que señaló Nino acerca de la superfluidad del Derecho como horizonte comprensivo, tanto de sus propias normas jurídicas, como de las conductas que pretende regular. Si el Derecho y el obrar se muestran inteligibles o comprensible a través de su referencia al OMI ¿por qué no nos ahorramos el paso intermedio del Derecho y posamos la mirada de forma directa en el OMI?

Nino cree resolver la relevancia interpretativa del Derecho a través de un recurso llamativamente parecido al que propone Ronald Dworkin: el Derecho no remite a cualquier norma ni valor moral, sino a los principios de justicia y moral social, y no a cualquier moral social, sino a la moral social que la práctica en su conjunto ha incorporado en el conjunto total de sus normas. Por lo mismo, el intérprete no puede situarse en cualquier horizonte comprensivo para determinar el sentido de las normas jurídicas individuales o para atribuir un significado jurídico a las conductas, sino en el horizonte comprensivo provisto por la práctica jurídica dentro de la cual se inserta la norma interpretada.

En una línea sustancialmente semejante, diría Ronald Dworkin que el horizonte comprensivo apropiado para interpretar normas y conductas dentro de una práctica jurídica es el que proveen los principios y valores de la moralidad que la práctica en su conjunto ha hecho suya ${ }^{104}$. Puesto en términos de metodologías interpretativas, tanto Ronald Dwor-

\footnotetext{
101 BLANCO (2002) p. 153.

102 Blanco (2002) pp. 155-156. Una crítica parecida, aunque desde otros prespuestos, en BenENTE (2012) pp. $124-142$.

103 Cfr., al respecto, Cianciardo (2014).

104 Cfr. Dworkin (1986b) pp. 225-275.
} 
kin como Nino parecen proponer que la interpretación sistemática no es una opción, sino una necesidad lógica -performativa- que emana del hecho de que la interpretación se produce dentro de una práctica colectiva.

Hasta aquí el argumento es indiscutible. Se participa de una práctica ajustando el obrar a sus reglas. Si quiero jugar al fútbol debo comenzar por conocer las reglas del fútbol y ajustar mi juego a estas reglas. Si en cambio ajusto mi obrar a las reglas del rugby, por mucho que desee e incluso crea jugar al fútbol, estaré jugando al rugby. Análogamente, podríamos decir que una condición necesaria para participar del "juego" del Derecho es jugar al Derecho y no, en cambio, a mi propio juego de intereses o incluso de convicciones morales. Participar del Derecho es ajustar la propia conducta a sus reglas para lo cual, por supuesto, primero hay que conocer las reglas. Solo desde ese preciso horizonte, y en relación con él, es que resulta inteligible cada una de las reglas que componen el sistema.

En esta línea argumental, cabe reiterarlo, en la medida en que la interpretación sistemática se propone adecuar la comprensión de las normas jurídicas al sentido u objetivo del resto de las normas que conforman una práctica, no es una opción metodológica. Es más bien una necesidad lógica performativa del acto de participar del Derecho. Quien pretende comprender las normas jurídicas desde un horizonte comprensivo que no encaja ( fit), como diría Dworkin, con el resto de las normas que conforman una práctica, no "juega al Derecho" sino a su propio juego.

No es pues de extrañar que las prácticas constitucionales y jurídicas en general hayan hecho suya la regla interpretativa de coherencia, según la cual el intérprete ha de optar por la interpretación que mejor se ajuste, no solo a decisiones anteriores del mismo tribunal, sino al conjunto total de normas y decisiones que integran la práctica sistemáticamente considerada. Desde esta perspectiva, pareciera que tanto Ronald Dworkin como Carlos Nino toman nota, no solo de una necesidad lógica, sino también de una cualidad fenomenológica de la práctica contemporánea del Derecho.

Pero ni las necesidades lógicas performativas ni las cualidades fenomenológicas son fuentes válidas de exigencias morales, salvo que se admita la existencia de una norma moral que obligue a obrar con coherencia performativa, en el primer caso, o de una norma moral que obligue a ser fiel a las cualidades fenomenológicas de las prácticas en las cuales se participa, en el segundo. En realidad, la segunda sería la concreción de la primera: la coherencia performativa en el plano del Derecho se realiza mediante el ajuste del obrar individual a las cualidades fenomenológicas del Derecho y, más concretamente todavía, a su naturaleza sistemática. Como sea, en ausencia de una y otra regla moral, no caben argumentos para cuestionar la pretensión de que mientras se goce de imperium para hacerle decir al Derecho lo que se quiera, así se hará, aun cuando se tenga conciencia que el Derecho sistemáticamente considerado dice otra cosa.

Ronald Dworkin se animó a afrontar el desafío de justificar moralmente -y no solo lógicamente- la obligación de coherencia interpretativa, apuntando que no se trata simplemente de un modo de darse el Derecho en las prácticas constitucionales, sino de una manifestación del deber de justicia. La coherencia interpretativa sería, más concretamente, una dimensión del valor de la igualdad, que es a su vez una dimensión de la justicia. Más arriba hemos sugerido otra respuesta posible que podría ofrecer Nino desde su particular concep- 
ción del Derecho como fuente de conocimiento del OMI: dado que el proceso democrático es el más fiel intérprete de los principios de moralidad social y de justicia del OMI, el intérprete hace bien en dejarse guiar por el primero en su conjunto a la hora de intentar comprender los segundos. Nino podría agregar pues al argumento de lógica performativa a favor de la interpretación sistemática un argumento moral como el de Dworkin, según el cual la coherencia interpretativa es un modo de realizar la exigencia de justicia postulada por el OMI.

Ahora bien, como toda indagación acerca de los fundamentos de una exigencia normativa, la pregunta por la obligatoriedad de la perspectiva sistemática de interpretación puede continuar desplegándose hasta el infinito. De modo que, al igual que ocurre con la obligatoriedad del Derecho en general, Nino habrá de admitir que o bien esta obligación es intrínsecamente razonable, o bien se deriva de forma racional a partir de alguna otra norma intrínsecamente razonable. De lo contrario, la exigibilidad del deber de coherencia interpretativa se esfumaría en un regreso al infinito o en la derivación falaz a partir de hechos sociales.

Supongamos pues por el momento que Nino está dispuesto a aceptar que la obligación moral de interpretar el Derecho en forma armónica, coherente o sistemática deriva de normas morales que son intrínsecamente razonables (y por lo mismo, independientes de toda praxis social). Lo que sin embargo sabemos con certeza es que Nino no está dispuesto a aceptar que estas normas intrínsecamente razonables puedan conocerse con independencia de la praxis del Derecho, desde el momento en que el Derecho democráticamente producido es el modo más genuino y fiable de acceder cognitivamente a estas normas intrínsecamente razonables. Pero entonces la circularidad tautológica que afecta a la cadena de justificación de la obligatoriedad del Derecho se proyecta ahora sobre la inteligibilidad del Derecho o, lo que es lo mismo, sobre la cadena de sentido.

En efecto, en la medida en que el OMI se expresa por boca del Derecho, y solo a través del Derecho, también se disuelve materialmente en el Derecho. Volvamos al punto de arranque: ante lo innegable de la "creatividad interpretativa" o de la presencia de un margen de elección moral en la interpretación del Derecho, aparecía la pregunta por la relevancia del Derecho, no ya como motivador de la acción, sino como guía epistémico. Si el sentido de las normas jurídicas se encuentra y se determina por referencia a normas morales, ¿por qué no dejarse guiar de forma directa por las segundas? Nino responde, en línea con Dworkin: porque las normas morales no guían por sí mismas el obrar, sino a través del Derecho. Las normas morales se expresan a través del Derecho, y solo en la medida en que se expresan por vía del Derecho constituyen guías epistémicas del obrar.

Es posible que con esta respuesta se haya salvado el problema de la superfluidad del Derecho. Pero ahora lo superfluo parece ser la moral pues, ¿cómo distingue el intérprete entre el material normativo jurídico y el material normativo del OMI, cuando es el propio Derecho el que manifiesta el contenido del segundo? El rol del orden moral en la cadena de sentido era servir de horizonte comprensivo del Derecho allí donde el Derecho abría un espacio para la creatividad interpretativa.

Este rol iluminador de la moral planteaba el problema de la relevancia del Derecho como guía epistémico del obrar, allí donde el Derecho se integraba con la moral para ser capaz de decir algo. Pero ahora resulta que la moral solo habla a través del Derecho. De forma tal que se ha privado al intérprete de todo horizonte comprensivo diferente del propio Dere- 
cho para determinar el sentido de las normas jurídicas. Tanto de las que hablan por sí mismas -si es que estas normas existen-, como de las que hablan con el auxilio de la luz moral.

El Derecho remite al intérprete a la moral, a través de la exigencia de razonabilidad, como horizonte para realizar las elecciones ínsitas en todo proceso de interpretación. Pero la moral remite al Derecho. ¿Qué consecuencias prácticas tiene esta circularidad interpretativa? Como toda respuesta tautológica no es una respuesta válida. Lo que ocurre, en definitiva, es que los márgenes de creatividad interpretativa se han transformado en márgenes de discreción absoluta... Si la moral se expresa a través del Derecho, el intérprete no puede hacer otra cosa que indagar al mismo Derecho en los márgenes de elección o creatividad interpretativa. Pero como precisamente es el Derecho el que manifiesta estos márgenes de creatividad, se abren solo dos alternativas: o bien el Derecho ofrece una única respuesta, o bien ofrece más de una respuesta y ninguna indicación acerca de cómo guiar la conducta. La solución auténtica a estos problemas exige mostrar un "stopper", no meramente formal: a) que hay valores o bienes materiales que dan razón de la exigencia de coherencia dentro de la propia práctica, y que cortan la remisión al infinito evadiendo la falacia naturalista; b) que hay una concepción antropológica muy concreta que permite distinguir entre aquellos asuntos en los que nos debemos al bien común, y aquellos en los que no -aquello en lo que el Derecho tiene competencia y aquello en lo que no-. La exigencia de que el Derecho se cuele en el razonamiento práctico no es, como dice Nino, universal, sino acotada a un tipo de asuntos. Pero ¿cuáles? No nos lo puede decir el Derecho...

Dicho esto mismo de otro modo, Nino acierta en el diagnóstico, pero yerra en la terapéutica. Acierta:

a) al detectar que el Derecho no puede ser justificado (tanto en el plano de su validez como en el de su obligatoriedad) ni interpretado sin remisión a un OMI;

b) cuando señala que la relación del Derecho respecto de un OMI pone en riesgo su inteligibilidad (ese y no otro es el sentido de la "paradoja de la irrelevancia"): por un lado -primera alternativa-, un Derecho desconectado del OMI no puede ser justificado ni interpretado, y, además, una descripción del Derecho que prescinda de esa conexión no puede hacerse cargo de la pretensión de razonabilidad (vía proscripción de la arbitrariedad) presente de modo explícito en la cultura de derechos; por otro lado -segunda alternativa-, un Derecho conectado con un OMI abre la pregunta de por qué no directamente regirse por este último;

c) cuando -asumida la existencia de la conexión entre el Derecho un OMI- detecta que la especificidad del razonamiento jurídico radica en su condición de práctica colectiva (en el sentido de práctica mediada por instituciones o institucional, agregaríamos nosotros).

Nino se equivoca, en cambio, en su descripción de la conexión y del OMI; esto ocurre porque teme decir demasiado (teme incurrir en un dogmatismo), y acaba afirmando tan poco que lo que dice conduce a un callejón sin salida ${ }^{105}$. Siendo el Derecho la vía epis-

105 Cfr., al respecto, Montero (2006) pp. 327-330. 
témica que permite conocer al OMI, llega a afirmar que en un régimen democrático existe una obligatoriedad moral de obedecer al típico producto de la democracia, la ley, porque su contenido equivale, con toda probabilidad, al contenido del OMI. El autor argentino incurre, así, en una circularidad tautológica que frustra lo que pretendía al comienzo de su trabajo: dotar al Derecho de justificación y de una vía que preservara la razonabilidad de su interpretación, y a través de uno y otro paso, que diera cuenta de su inteligibilidad. Teniendo en cuenta lo anterior, resulta necesario, entonces, explorar un camino alternativo que permita alcanzar estos objetivos. Se trata de una tarea pendiente que se pretende emprender en trabajos futuros.

\section{BIBLIOGRAFÍA CITADA}

AlEXY, Robert (1997): Teoría de la argumentación jurídica. La teoría del discurso racional como teoría de la fundamentación jurídica (Madrid, Centro de Estudios Constitucionales).

AleXY, Robert (2008): “On the Concept and the Nature of Law”, Ratio Juris Vol. 21 No. 3: pp. 281-299.

Austin, John (1981): Sobre la utilidad del estudio de la Jurisprudencia (traducción y estudio preliminar de Felipe González Vicén, Madrid, Centro de Estudios Constitucionales).

Benente, Mauro (2012): "El platonismo en la democracia deliberativa de Carlos Nino", Isonomía, 36: pp. 117-145.

Blanco, Susana (2002): Positivismo metodológico y racionalidad política. Una interpretación de la teoría jurídica de Carlos S. Nino (Granada, Comares).

Burton, Steven (1989): “The Work of Joseph Raz: Law as Practical Reason”, Southern California Law Review, 62: pp. 747-794.

Cianciardo, Juan y Pilar Zambrano (2014): "Los a priori de la cultura de derechos", en evaluación en el Boletín Mexicano de Derecho Comparado.

Cianciardo, Juan (2014): "A Culture of Rights, The Fall of Frontiers and Natural Law", aceptado en The Journal of Comparative Law, Wildy and Sons Ltd., London.

Coтta, Sergio (1987): El Derecho en la existencia humana. Principios de ontofenomenología jurídica (ed. española a cargo de I. Peidro Pastor, Pamplona, Eunsa).

CotтA, Sergio (1991): Il Diritto nell'Esistenza. Linee di ontofenomenologia giuridica, seconda edizione riveduta e ampliata (Milano, Giufrè Editore).

De LuCAS, F. Javier (1982): "La pregunta fundamental. Una precisión metodológica", en Persona y Derecho 9: pp. 121-125.

Dworkin, Ronald (1986a): A Matter of Principle (Oxford, Clarendon Press).

DwOrkIn, Ronald (2011): Justice for Hedgehogs (Cambridge, Harvard University Press).

Dworkin, Ronald (1986b): Law's Empire (Cambridge Mass., Harvard University Press).

Dworkin, Ronald (1977): Taking Rights Seriously (London, Duckworth).

Finnis, John (2000): Ley natural y derechos naturales (C. OrRego, Buenos Aires, AbeledoPerrot).

Grepri, Andrea (2008), “Consenso e imparcialidad. Sobre la justificación moral de la democracia en el pensamiento de C. S. Nino”, en Carlos Rosenkratz y Rodolfo Vigo 
(comps.), Razonamiento jurídico, ciencia del derecho y democracia en Carlos S. Nino (México, Fontamara) pp. 221-259.

Hart, Herbert (1994): The Concept of Law (Oxford Edit., Clarendon Press) Segunda edición. Hervada, Javier (1982): "Problemas que una nota esencial de los derechos humanos plantea a la filosofía del derecho", Persona y Derecho 9: pp. 243-256.

Kelsen, Hans (1960): Reine Recthslehre (Zweite, Wien). Se cita de la ed. en español: (1982): Teoría pura del derecho (trad. R. J. Vernengo, México, Universidad Autónoma de México).

Montero, Julio (2006): "La concepción de la democracia deliberativa de C. Nino: ¿populismo moral o elitismo epistemológico?", Doxa. Cuadernos de Filosofía del Derecho 29: pp. 319-331.

Moore, Michael, S. (1989): "Symposium: The Works of Joseph Raz: Authority, Law, and Razian Reasons": pp. 897-896.

Nino, Carlos (1986): "La paradoja de la irrelevancia moral del gobierno y el valor epistemológico de la democracia”, Análisis Filosófico VI-2: pp. 65-82.

Nino, Carlos (1991): "The Epistemological Moral Relevance of Democracy”, Ratio Iuris 4, nro. 1: pp. 36-51.

Nino, Carlos (1989): Consideraciones sobre la dogmática jurídica (con referencia particular a la dogmática penal) (México, UNAM).

Nino, Carlos (1994): Derecho, Moral y Política. Una revisión de la teoría general del Derecho, Barcelona, Ariel).

Nino, Carlos (1989): El constructivismo ético (Madrid, Centro de Estudios Constitucionales).

Nino, Carlos (1984): Ética y derechos humanos (Buenos Aires, Paidós).

Nino, Carlos (1989): Ética y derechos humanos. Un ensayo de fundamentación (Buenos Aires, Astrea).

Olivecrona, Karl (1939): Law as fact (Copenhague-Londres, Einar Munksgaard-Humphrey Milford).

Olivecrona, Karl (1971): Law as fact (Londres, Stevens \& Sons).

Orrego, Cristóbal (2010): "Supuestos conflictos de derechos humanos y la especificación de la acción moral”, Revista Chilena de Derecho, vol. 37 No 2: pp. 311-342.

Perry, Stephen (2005): "Symposium on Natural Law and Natural Rights: Law and Obligation”, American Journal of Jurisprudence, 50: pp. 264-265.

Perry, Stephen, R., "The Works of Joseph Raz: Second-Order Reasons, Uncertainty and Legal Theory", Southern California Law Review, 62: pp. 913-994.

RAz, Joseph (2004): "Incorporation by Law", Legal Theory, 10: pp 1-17.

RaZ, Joseph (2001): "Reasoning with Rules”, Current Legal Problems, 54: pp. 1-18.

Raz, Joseph, (1989): "Symposium: The Works of Joseph Raz: Facing Up: A Reply", Southern Carlifornia Law Review, 62: 1153-1236.

Raz, Joseph (2006): “The Problem of Authority. Revisiting the Service Conception”, Minnesota Law Review, 90: pp. 1003-1045.

Raz, Joseph (1999): Practical Reason and Norms (Oxford University Press).

Raz, Joseph (1991): Razón práctica y normas (trad. J. Ruiz Manero, Madrid, Centro de Estudios Constitucionales). 
Raz, Joseph (1979): The Authority of Law. Essays on Law and Morality (Oxford, Clarendon Press), se cita en la versión en español (1991): Razón práctica y normas (trad. J. Ruiz Manero, Madrid, Centro de Estudios Constitucionales).

Raz, Joseph (1986): The Morality of Freedom (New York, Clarendon Paperbacks, Oxford University Press).

RódenAS, Ángeles (1991): "Sobre la justificación de la democracia en la obra de Carlos S. Nino", Doxa: Cuadernos de Filosofía del Derecho 10: pp. 279-293.

RÓDENAS, Ángeles (1996): Sobre la justificación de la autoridad (Madrid, CEC).

Romano, Bruno (2010): “Sergio Cotta (1920-2007): l' «ontofenomenologia» ed «il diritto nell' esistenza»", en Bruno Romano (2010): Sergio Cotta (1920-2007). Scritti in memoria, Quaderni della Rivista Internazionale di Filosofia del Diritto, Milano, Giufrè Editore: pp. 11-20.

Ross, Alf (1997): Sobre el Derecho y la justicia (trad. de G. Carrió, Buenos Aires, Eudeba).

Stone Sweet, Alex (2012): “Constitutional Courts”, en Rosenfeld, Michel and András SAJÓ (eds.) (2012), The Oxford Habdbook of Comparative Constitutional Law (Oxford, Oxford University Press) pp. 816-830.

Vergara Lacalle, Óscar (2004): El Derecho como fenómeno psicosocial. Un estudio sobre el pensamiento de K. Olivecrona (Granada, Comares).

Zambrano, Pilar (2007): "Objetividad en la interpretación judicial y objetividad en la moral. Una reflexión a partir de las luces y sombras en la propuesta de Ronald Dworkin”, Persona y Derecho 56: pp. 281-326.

Zambrano, Pilar (2012): "El derecho como razón excluyente para la acción. Una aproximación desde la teoría iusnaturalista de John Finnis", en Cianciardo, J. et al., Razón Jurídica y Razón moral. Un estudio sobre la valoración ética en el Derecho, México: Porrúa: 71-100. 